\title{
Genomic stock structure of the marine teleost tarakihi (Nemadactylus macropterus) provides evidence of fine-scale adaptation and a temperature-associated cline amid panmixia
}

\author{
1 Yvan Papa ${ }^{1 *}$, Mark A. Morrison², Maren Wellenreuther ${ }^{3,4}$, Peter A. Ritchie ${ }^{1}$ \\ $2{ }^{1}$ School of Biological Sciences, Victoria University of Wellington, Wellington, New Zealand \\ $3 \quad{ }^{2}$ National Institute of Water and Atmospheric Research, Auckland, New Zealand \\ $4{ }^{3}$ Seafood Production Group, The New Zealand Institute for Plant and Food Research Limited, \\ 5 Nelson, New Zealand \\ $6{ }^{4}$ School of Biological Sciences, The University of Auckland, Auckland, New Zealand \\ * Correspondence: \\ Yvan Papa \\ 10 yvanpapa@gmail.com
}

11 Keywords: fish, locus-environment association, New Zealand, population structure, seascape, 12 whole-genome sequencing.

\section{Abstract}

Tarakihi (Nemadactylus macropterus) is an important fishery species with widespread distribution around New Zealand and off the southern coasts of Australia. However, little is known about whether the populations are locally adapted or genetically structured. To address this, we conducted wholegenome resequencing of 175 tarakihi from around New Zealand and Tasmania (Australia) to obtain a dataset of 7.5 million genome-wide and high-quality single nucleotide polymorphisms (SNPs).

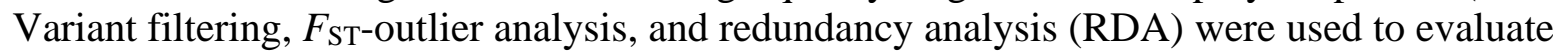
population structure, adaptive structure, and locus-environment associations. A weak but significant level of neutral genetic differentiation was found between tarakihi from New Zealand and Tasmania $\left(F_{\mathrm{ST}}=0.0054-0.0073, P \leq 0.05\right)$, supporting the existence of at least two separate reproductive stocks. No clustering was detected among the New Zealand populations $\left(\Phi_{\mathrm{ST}}<0.001, P=0.77\right)$. Outlier-based, presumably adaptive variation suggests fine-scale adaptive structure between locations around central New Zealand off the east (Wairarapa, Cape Campbell, and Hawke's Bay) and the west coast (Tasman Bay/Golden Bay and Upper West Coast of South Island). Allele frequencies from 55 loci were associated with at least one of six environmental variables, of which 47 correlated strongly with yearly mean water temperature. Although genes associated with these loci are linked to various functions, the most common functions were integral components of membrane and cilium assembly. Projection of the RDA indicates the existence of a latitudinal temperature cline. Our work provides the first genomic insights supporting panmixia of tarakihi in New Zealand and evidence of a genomic cline that appears to be driven by the temperature gradients, together providing crucial information to inform the stock assessment of this species, and to widen the insights of the ecological drivers of adaptive variation in a marine species. 


\section{Introduction}

37 Effective fisheries management relies on the identification and delineation of stocks to enable optimal and sustainable utilization (Begg et al., 1999; Waples et al., 2008; Cadrin et al., 2014). Ideally, the ultimate goal of fisheries management is to harvest each separate stock at a rate that matches their level of recruitment when taking into account natural mortality (Beddington et al., 2007; Zhou et al., 2019). Discrepancies between the stock management units and the boundaries of biological units can result in overexploitation (Laikre et al., 2005; Reiss et al., 2009; Benestan, 2019), which if left unchecked, could lead to the decline, and ultimately the collapse, of a stock (Orensanz et al., 1998; Ying et al., 2011; Cadrin, 2020). However, biologically accurate information about stock boundaries is still lacking for the vast majority of fisheries species, particularly those residing in the New Zealand Exclusive Economic Zone (Papa et al., 2021b).

Marine environments often contain few physical barriers when compared to freshwater or terrestrial environments. Therefore, the levels of genetic divergence among groups of marine fishes are often expected, and found, to be low (e.g. Koot et al., 2021). This is especially true for marine species with large population sizes and high potential for larval and/or adult dispersal (Ovenden, 2013; Lal et al., 2016; Sandoval-Castillo et al., 2018). Traditional genetic markers (e.g. microsatellites or mitochondrial sequences), that typically represent a very small proportion of the genome, often do not provide the level of resolution required to detect fine-scale genetic structure. However, not detecting any significant genetic differentiation does not necessarily mean there is a level of migration relevant to fisheries management. Populations could be demographically independent but only recently sundered, there could still be some low level of gene flow, or effective population size could be high, with differentiation caused by drift happening slowly (Benestan et al., 2015; Attard et al., 2018). Moreover, when variation is detected with low-resolution markers, it is typically very difficult to determine whether the observed variation is neutral (i.e. due to the accumulation of random mutations through e.g. genetic drift) or adaptive (i.e. due to natural selection which leads to local adaptation) (Carvalho and Hauser, 1994; Allendorf et al., 2010).

In contrast to low-resolution traditional genetic markers, next-generation-sequencing technologies can produce very large genome-wide datasets that have two advantages: (1) a vast increase in the number of available neutral loci, which can meet the level of resolution required when testing for genetic differentiation in marine species, and (2) the ability to detect genomic regions that are currently, or at some time in the recent past, experiencing selection (Bernatchez et al., 2017; Benestan, 2019; Papa et al., 2021b). Previously unknown population structure has been detected in several marine species using genome-wide single nucleotide polymorphism (SNP) datasets. They include the American lobster (Benestan et al., 2015), yellowfin tuna (Pecoraro et al., 2018), silky shark (Kraft et al., 2020), green abalone (Mejía-Ruíz et al., 2020), and California market squid (Cheng et al., 2021). Even when populations display little to no neutral genomic differentiation, adaptive population structure can be detected through outlier-based methods (e.g. albacore (Vaux et al., 2021)) or environment association methods (e.g. American lobster (Benestan et al., 2016), summer flounder (Hoey and Pinsky, 2018), or greenlip abalone (Sandoval-Castillo et al., 2018)).

Tarakihi (Nemadactylus macropterus (Forster 1801)) (Figure 1A) is a demersal marine fish species with an expansive distribution, being widely found in the inshore areas of New Zealand (Figure 2). The species occurs from the Three Kings Islands in the north to the Snare Islands in the south and the Chatham Islands in the east, at depths of 10 to $250 \mathrm{~m}$ (Annala, 1987; Roberts et al., 2015). It is also 79 distributed along the southern inshore areas of Australia, including Tasmania (Roberts et al., 2015). 
phase for approximately 10 months (Annala, 1987; Roberts et al., 2015) (Figure 1B). During this

83 period, their dispersal is mainly driven by oceanic currents, where mixing of individuals from different spawning areas can occur (Bruce, 2001). After c. 10 months, post-larvae morph into juveniles and settle in shallow nursing grounds (Vooren, 1972) (Figure 1C). Adults can live for more than 30 years and have the potential to disperse over large distances, sometimes hundreds of kilometers (Annala, 1987; Hanchet and Field, 2001). Tarakihi are mainly caught by bottom trawling at depths of about $250 \mathrm{~m}$. Commercial catches in New Zealand are around 5,000 tons per year over the past 30 years, with a very recent reduction to 4,400 tons for the fishing year 2019-2020 (Fisheries New Zealand, 2021). While tarakihi are commercially caught in all the unprotected Quota Management Areas of the New Zealand Exclusive Economic Zone, the majority of catches (c. 80\%) occur off the east coast of the North and South Island (Langley, 2018). The spawning biomass in some areas (TAR1, TAR2 and TAR3, Figure 2) are thought to be below the fisheries management soft limit (20\% of the unexploited, equilibrium biomass) since the early 2000s (Langley, 2018). Consequently, the total allowable commercial catch (TACC) was reduced in 2018 and again in 2019 for these areas, which is the first reduction in tarakihi TACC since the 1980s (Fisheries New Zealand, 2021). The observed declines highlight the need for evidence-based management strategies that incorporate best knowledge about the biological stock structure of this species. However, both stock structure and the levels of connectivity among fished areas are poorly known for this species.

DNA-based markers are particularly appropriate to provide evidence for stock boundaries, especially if a population has experienced long-term (total or partial) reproductive isolation (Waples et al., 2008; Ovenden et al., 2015; Cadrin, 2020). Six population genetic studies have been conducted on tarakihi in an effort to resolve its stock structure. Four of these studies investigated samples from around Australia and included only one location from New Zealand, using allozyme electrophoresis (Richardson, 1982; Elliott and Ward, 1994), mitochondrial DNA restriction fragment length polymorphism (Grewe et al., 1994), and microsatellite DNA markers (Burridge and Smolenski, 2003). No significant genetic structure among Australian stocks was detected. Weak but significant genetic divergence was found between New Zealand and Australia (Richardson, 1982; Elliott and Ward, 1994; Grewe et al., 1994), except in one study (Burridge and Smolenski, 2003). Two genetic studies have been conducted among New Zealand locations. The first study (Gauldie and Johnston, 1980) was conducted on c. 3,000 samples from around New Zealand. Significant population genetic differentiation was observed based on allelic frequencies at the phosphoglucomutase allozyme locus, which led to the proposition of eight geographical stock boundaries around the North and South Island (see Gauldie \& Johnston (1980) for more details on these putative stock boundaries). However, it was not possible to rule out a deviation from selective neutrality for that locus. Indeed, the authors emphasized that the observed differences in allele frequencies might not be indicative of differentiation due to reproductively separated stocks, but were most probably due to an adaptive cline related to water temperature. The second study used direct sequencing of the mitochondrial DNA control region from 370 tarakihi collected around New Zealand main islands and Chatham Islands (Papa et al., 2021a). While again no overall genetic structure was found among New Zealand and Chatham Island populations, two weak genetic disjunctions were detected. The first was between the west and east coasts of the South Island, which would be consistent with biological observations based on age and size structure (Langley, 2018). The second was between Hawke's Bay and East Northland (but not the locations between them), which may be indicative of a complex migration pattern along the east coast of North Island. 
sampling locations, and 3) evaluate the relationship between genetic differentiation and

130 environmental factors. The results are compared to the current fishery stock hypotheses for tarakihi.

\section{Materials and Methods}

\section{$132 \quad 2.1 \quad$ Sampling and DNA extraction}

133 One hundred eighty-eight samples were used, including 161 tarakihi from New Zealand, 14 tarakihi

134 from Tasmania and 12 king tarakihi (Nemadactylus n.sp.) from the north of New Zealand (Figure 2,

135 Table 1). The king tarakihi phenotype is similar to tarakihi and is managed as part of the same

136 fisheries (Figure 1D). Samples from king tarakihi were included to compare the observed levels of

137 diversity with a close taxon. An additional specimen, caught in a fishing competition in Gisborne

138 (East Cape), was visually identified as a king tarakihi and was added to the dataset (referred to as

139 "GBK" for Gisborne king tarakihi). All 188 samples were sourced from specimens captured during

140 two sampling phases. The first sampling phase took place between October 2017 and April 2018 and

141 aimed at collecting specimens from all around New Zealand for a previous study on the population

142 genetics of tarakihi based on a mitochondrial marker (Papa et al., 2021a). All specimens were sourced from commercial fishing companies (which in some cases conducted specific tows targeting tarakihi) with the exception of Fiordland samples that were provided by recreational fishers. Although most of the tissues collected during the first sampling phase were suitable for Sanger sequencing as applied in the mitochondrial study, DNA in these samples was generally too degraded for Illumina library preparation and whole-genome sequencing. As a result, 46 samples from phase 1 that passed the quality controls criteria were used in this study. The remaining 142 samples came from specimens captured during a second sampling phase from January 2019 to June 2020. This included fish captured by commercial fishing companies and/or as part of a broader monitoring campaign from the National Institute of Water and Atmospheric Research (NIWA), as well as specimens captured during recreational fishing competitions. An additional 14 specimens captured off Tasmania were purchased at a Sydney market through the New South Wales Department of

154 Primary Industries program.

Tail muscle (phase 1) or pectoral fin (phase 2) tissue was collected from the specimens and immersed in $99 \%$ ethanol (phase 1 and 2) or DESS solution (20\% DMSO, 0.25 M EDTA, NaCl saturated) (phase 2) and then stored at $-20^{\circ} \mathrm{C}$. DESS was found to be more suitable to preserve DNA when tissue is sampled in the field (Oosting et al., 2020), which is generally the case when dealing with wild fisheries specimens. Total genomic DNA was extracted with a rapid salt-extraction protocol (Aljanabi and Martinez, 1997) that included an RNase step, suspended in 30-150 $\mu 1$ Tris-EDTA buffer (10 mM Tris- $\mathrm{HCl} \mathrm{pH} 8.0,0.1 \mathrm{mM}$ EDTA), and stored at $-20^{\circ} \mathrm{C}$. The quantity of Tris-EDTA was chosen based on visual assessment of the size of the DNA pellet. A low concentration of EDTA $(0.1 \mathrm{mM})$ was used to reduce the risks of enzymatic inhibitions during library preparation. The integrity of extracted DNA samples was assessed by visualising the presence of high molecular weight DNA with agarose gel electrophoreses. Electrophoreses were run in TBE-buffered $1 \%$ agarose gels at $90 \mathrm{~V}$ and $400 \mathrm{~mA}$ for $30 \mathrm{~min}$. Samples were visually classified as high, medium, or low weight depending on the intensity of DNA > $20 \mathrm{~Kb}$ as measured with a Lambda HindIII DNA ladder. Purity of DNA samples was measured with a NanoPhotometer® NP80 (Implen). Readings of 260/280 were classified as good (1.8-1.95), medium (1.6-2) or bad (any other value). Similarly, $260 / 230$ values were classified as good $(\geq 2)$, medium $(\geq 1.4)$, or bad. Quantity of double-strand DNA was measured using a Qubit ${ }^{\mathrm{TM}}$ dsDNA BR Assay Kit. Samples were classified based on dsDNA concentration in a final volume of $100 \mu \mathrm{l}$ as follows: high $(\geq 50 \mathrm{ng} / \mu \mathrm{l})$, medium $(\geq 5 \mathrm{ng} / \mu \mathrm{l})$, 
173 or low $(<5 \mathrm{ng} / \mu \mathrm{l})$. DNA samples were selected based on both quality and geographic representation

174 for DNA library preparation and sequencing.

\section{$175 \quad 2.2$ Whole-Genome Sequencing}

176 A total of 188 DNA samples were selected for whole-genome sequencing. An effort was made to sequence at least 10 specimens per sampling location, however, this could not be achieved for seven out of 18 locations. In particular, only a few DNA samples of sufficient quality could be obtained for remote locations that were sampled only in phase 1 (Chatham Islands and Fiordland). Nevertheless, a good overall representation of tarakihi fishing areas around mainland New Zealand was obtained (Figure 2), especially in the most fished management areas (TAR1, TAR2, and TAR3). DNA samples were diluted to an equal volume of $80 \mu \mathrm{l}$ with a DNA concentration of $30 \mathrm{ng} / \mu \mathrm{l}$ (sometimes lower when not possible) and sent to the Australian Genome Research Facility (AGRF, Melbourne, Australia) for DNA library preparation and sequencing. The Illumina DNA shotgun library was prepared following the Nextera DNA FLEX low volume protocol with Nextera DNA Combinatorial Dual Indexes (Illumina) for insert sizes 300-350 bp. Sequencing of 150 bp paired-end reads was performed on NovaSeq 6000 (Illumina) with NovaSeq 6000 S4 Reagent Kit and NovaSeq XP 4-Lane Kit for 300 cycles. Each lane contained 96 wells, and each individual was sequenced in one well. Since the sequencing yield of each lane was 700-800 Gb, it was expected that each individual would be sequenced for c. $8 \mathrm{~Gb}$. The genome size was estimated to be around $700 \mathrm{Mb}$ based on the C-value of 0.72 for Cheilodactylus fuscus on the Animal Genome Size Database (http://www.genomesize.com). The sequencing coverage was thus estimated to be c. $11 \times$ per sample. Base calling, quality scoring, and de-multiplexing were performed by sequencing provider with RTA3 software v3.3.3 and Illumina bcl2fastq pipeline v2.20.0.422.

\subsection{Quality control and pre-processing}

The quality of the paired-end reads was assessed with FastQC v0.11.7 (Andrews, 2018) and MultiQC v1.7 (Ewels et al., 2016) before and after trimming. Raw reads were trimmed for adapter contamination and unpaired reads were filtered out using Trimmomatic v0.39 (Bolger et al., 2014) with the following parameters: paired-end mode, phred 33 base quality encoding, maximum allowed mismatch count $=2$, match accuracy between adapter-ligated reads $=30$, match accuracy between adapter and read $=10$. Nextera adapters were targeted using the file NexteraPE-PE. fa provided by Trimmomatic.

\subsection{Genotyping}

Trimmed and filtered paired reads were mapped to the tarakihi reference genome (1,214 scaffolds) assembled in a previous study (Papa et al., 2021c) by using the Burrows-Wheeler Alignment (BWA) method with bwa-kit v0.7.15 (Li and Durbin, 2009). In brief, a BWA index was created for the reference genome, as well as a SAM index with SAMtools v1.9 (Li et al., 2009). For each specimen, the forward and reverse reads were mapped to the genome with the command bwa mem $-\mathrm{a}-\mathrm{M}$ to flag all single-end and unpaired reads and mark shorter split hits as secondary. Duplicated reads were marked using Picard v2.18.20 (Broad Institute, 2019) MarkDuplicates with default settings. Genotype likelihoods were produced from the BAM files using bcftools v1.9 (Li, 2011) command mpi leup. The minimum mapping quality was set to 10, the mapping quality downgrading coefficient was set to 50 for reads with excessive mismatches, and only reads mapped in proper pair were kept (e.g. no secondary alignment or duplicates). SNPs were then called with bcftools multiallelic caller on default parameters, outputting only variant sites and skipping indels. Genotype likelihoods and SNPs calling were both performed separately on each of the 1,214 assembly 
217 scaffolds and results were then merged into a genome-wide SNP dataset using bcftools concat. The

218 final BCF file was sorted and indexed after having renamed the headers.

\section{$219 \quad 2.5 \quad$ Variant filtering}

220 Several SNP datasets were produced and analysed separately in this study (Figure 3). The first was a pruned dataset that contained the 188 tarakihi and king tarakihi individuals, where SNPs were filtered for minimum quality criteria and pruned for linkage and Hardy-Weinberg disequilibrium. The second was a dataset of neutral SNPs (hereafter referred to as the "neutral dataset") that only included the 250 longest scaffolds from locations with $\geq 5$ sampled adult tarakihi individuals (king tarakihi, Fiordland, Chatham Islands, Tasman Bay/Golden Bay (TBGB) juveniles, and GBK were discarded). SNP filtering for the neutral dataset was identical to the pruned dataset but with an additional step of filtering out potentially adaptive outliers (see below). The 250 longest scaffolds were retained because (1) they contained more than $90 \%$ of the total number of bases in the tarakihi reference genome (L90 = 219 (Papa et al., 2021c)), (2) for computational efficiency, and (3) because the default parameters used for the OutFLANK analysis (see below) were not optimal anymore to fit the $F_{\text {ST }}$ curve in some scaffolds past that number, which means they would have had to be manually tuned for the c. 1,000 remaining scaffolds. Chatham Islands, Fiordland and the juvenile TBGB samples were discarded at that stage because of their low number of samples (two, three, and five, respectively), which was considered too low to confidently predict population allele frequencies. The GBK specimen was discarded because of its dubious field identification, and the king tarakihi were discarded for being a different species with a different demographic history. The third and fourth datasets were outlier-based, presumably adaptive datasets containing the same individuals and scaffolds as the neutral dataset, but including only strong candidates for adaptive loci (see below). The fifth, environment-adaptive, dataset was obtained through locus-environment association analysis (see below). Filtering of variant sites was performed with VCFtools v0.1.16 (Danecek et al., 2011). Filtering steps were primarily carried out separately on each scaffold, and resulting VCF files were merged with Picard v2.18.20.

Quality filtering: Only bi-allelic sites with a minimum quality of 600 were retained (--maxalleles 2 --min-alleles 2 --ming 600). The minimum allelic depth for sites in an individual was set to three and the mean depth of sites across all individuals was set between eight and twenty-five (-minDP 3 --min-meanDP 8 --max-meanDP 25). Sites that were missing in more than $5 \%$ of individuals and sites with a minor allele frequency lower than $1 \%$ were filtered out (--max-missing $0.95--m a f \quad 0.01)$. For each site, potential allelic imbalance was detected by running a binomial test on the sum of all reference alleles and the sum of all alternative alleles across all sequenced reads of heterozygous individuals with a custom $\mathrm{R}$ script, using the genotype (GT) and allelic depth (AD) format information. Sites were filtered out with VCFtools (-exclude-positions) if the total proportion of reference and alternative alleles was significantly different from $50 \%$ ( $P \leq 0.05$ after correction for false discovery rate) according to the binomial test. disequilibrium decay was plotted for the 30 longest scaffolds on the quality-filtered dataset. For this, the squared correlation coefficients between genotypes of sites separated by a maximum of 50,000 bp were calculated with VCFtools (--geno-r2 --ld-window-bp 50000). Nucleotide position and $R^{2}$ values for a random subset of a million sites in each scaffold were then plotted with a custom $\mathrm{R}$ script (Oosting, 2021). The analysis was run twice, once on the 188 individuals, and once without 260 including king tarakihi specimens. 
Pruning: Sites that were significantly deviating from Hardy-Weinberg equilibrium were filtered out, as well as sites occurring within a distance of $1,500 \mathrm{bp}$ from one another in the scaffolds (--hwe 0.05 --thin 1500). A minimum allele frequency of 0.01 was applied a second time. The presence of remaining linkage disequilibrium after thinning was detected with PLINK v1.90 (Chang et al., 2015), using a window size of 50 sites, shifting every five sites and using a pairwise $R^{2}$ threshold of 0.2 (--indep-pairwise 5050.2 ). These SNPs were then filtered out with VCFtools.

Neutral filtering: Sites that were potentially under selection were detected with OutFLANK v0.2 (Whitlock and Lotterhos, 2015) using default parameters. Loci flagged as outliers with a minimum heterozygosity of 0.1 (He $>0.1$ ) and a false discovery threshold below $1 \%$ (qvalues $<0.01$ ), were filtered out of the dataset with VCFtools.

Adaptive filtering: In parallel with the neutral filtering, OutFLANK v0.2 was used on the pruned dataset to flag outlier loci with a minimum heterozygosity of 0.1 and a false discovery threshold (qvalue) below 0.05 . This analysis was run twice: the sampling locations that were detected as differentiated were discarded between the first and second analyses to detect SNPs with finer population structure. After each analysis, a custom R script adapted from Oosting (2021) was used to select only the site with the highest $F_{\mathrm{ST}}$ in each non-overlapping 50,000 bp sliding window in order to obtain a set of independent, presumably adaptive SNPs.

\subsection{SNP data analysis}

280

Number of reads per individuals and mean GC content were reported with FastQC v0.11.7 and MultiQC v1.7. Mean read depth of variant sites and proportion of missing sites in each individual were calculated with VCFtools v0.1.16. Observed heterozygosity and number of fixed alleles were obtained with dartR v1.9.6 (Gruber et al., 2018). Analyses of Molecular Variance (AMOVA) were conducted on the neutral dataset with poppr v2.9.2 (Kamvar et al., 2014) using hierarchical models of several groupings based on management areas, New Zealand coasts, and sampling locations. Associated $p$-values were computed with ade4 v1.7.16 (Dray and Dufour, 2007) function randtest using 999 replicates. Principal component analyses (PCA) were run on the pruned, neutral, and adaptive SNP datasets with dartR v1.9.6 using default parameters and results were projected onto axes with ggplot2 v3.3.3 (Wickham, 2009). Successive K-means cluster identification and discriminant analyses of principal components (DAPC) were performed with adegenet v2.1.3 (Jombart, 2008). See parameters used in Supplementary Table 1.

Pairwise weighted $F_{\text {ST }}$ values (Weir and Cockerham, 1984) were computed with StAMPP v1.6.1 (Pembleton et al., 2013) on the neutral and adaptive datasets. Associated $p$-values and 95\% confidence intervals were generated by running 1,000 bootstraps across loci and a false discovery rate correction (Benjamini and Hochberg, 1995) was applied to the $p$-values. The pairwise weighted $F_{\text {ST }}$ values were plotted onto heat maps clustered via dendrogram using pheatmap 1.0.12 (Kolde, 2019). Population structure was tentatively inferred in the neutral dataset with fastSTRUCTURE v1.0.3 (Raj et al., 2014). The number of populations $(K)$ was tested from 1 to 10 , and the value of $K$ that best explained the observed structure was chosen with the utility tool chooseK.py.

A test of isolation by distance (IBD) was performed using a Mantel test (999 replicates) with ade4 v1.7.16 on the neutral SNP dataset. The analysis was restricted to the samples from New Zealand locations. The geographic distances between sample coordinates were estimated with gdistance v1.3.6 (van Etten, 2017) by applying a 'least-cost distance' model of geographic dispersal where 
travel is restricted to the ocean. For this, a shapefile of New Zealand was rasterized with raster v3.4.5 (Hijmans, 2019), and each cell grid corresponding to the ocean and the land were assigned movement costs of 0 and 1, respectively. Sampling location coordinates were obtained by calculating the mean between the start and stop trawl latitudes and longitudes provided by the fishing vessels, or approximated arbitrarily when not provided. Pairwise weighted $F_{\text {ST }}$ values between sampling locations were used for the matrix of genetic distances.

\section{$\begin{array}{lll}310 & \mathbf{2 . 7} & \text { Genotype-environment association analysis }\end{array}$}

311 Environmental feature data was obtained with the R package sdmpredictors v0.2.9 (Bosch, 2020).

312 The complete dataset available from Bio-ORACLE v1, v2.1, and MARSPEC (Tyberghein et al., 2012; Sbrocco and Barber, 2013; Assis et al., 2018) was compiled into a total environmental dataset of 362 variables. Since the locus-environment association method used is a regression-based analysis, it was necessary to check for collinearity (i.e. non-independence) between the environmental variables before proceeding (Dormann et al., 2013). This was done in several steps. First, the 362 variables were manually clustered into groups that each measured the same physical, chemical, or biological process (Supplementary Table 2). As an example, the group "dissolved oxygen", included 25 variables, such as sea surface mean concentration, minimum concentration at mean depth, or concentration range at the bottom. For each of these groups, the R package psych v2.1.3 (Revelle, 2021) was used to assess the correlation level among variables. A set of weakly correlated variables (Pearson correlation $\left|R^{2}\right|<0.7$ ) was manually selected from each group and compiled in a second dataset of 48 variables (Supplementary Figure 1). The Pearson correlation and associated significance were computed among these 48 variables with the R package Hmisc v4.5-0 (Harrell, 2021). All variables that were significantly correlated to "mean temperature at mean depth" $(P \leq 0.05)$ were discarded. Temperature was chosen because it is usually correlated with many other environmental variables as it is associated with, or drives, many physical, chemical, and biological processes, and the mean value at mean depth was chosen to reflect the biology of tarakihi, which is a demersal, inshore species. Variables that were considered to be not biologically relevant for the studied species (cloud fraction, ice cover, East/West aspect and North/South aspect) were also discarded. This led to a third dataset of nine variables (Supplementary Figure 2). Three variables (profile curvature, plan curvature, and mean chlorophyll concentration at minimum depth) were further discarded for being correlated to concavity and mean primary production at the bottom $\left(\left|R^{2}\right|>0.5, P<0.001\right)$. This reduced the dataset to a final six lowly correlated variables: salinity range at mean depth, mean primary production at minimum depth, concavity (which is indicative of the location being on a slope or in a valley), mean temperature at mean depth, mean diffuse attenuation coefficient (indicator of water clarity), and mean iron concentration at the sea surface (Supplementary Figure 2).

Association between genotypes and environmental variables was assessed using a Redundancy Analysis (RDA). RDA is a multivariate, ordination-based locus-environment association method that is effective at detecting local adaptation on multiple loci under numerous demographical, biological, and sampling scenarios (Rellstab et al., 2015; Forester et al., 2016, 2018). The analysis was performed separately on the eight longest scaffolds using the quality-filtered SNP dataset (Figure 3), without including king tarakihi, GBK, specimens from Tasmania, and juveniles from TBGB. Missing genotype data was estimated using the most common genotype at each locus. The RDA was run with the package vegan v2.5.7 (Oksanen et al., 2020) on the genotype data and the six environmental variables cited above, with parameter scale $=$ TRUE to scale observations to unit variance. The significance of each RDA model, as well as each constrained axis, was assessed with vegan v2.5.7 function anova. CCa using 999 permutations. Loci that were strong candidates for local adaptation were selected by identifying the SNPs with scores \pm 3.5 standard deviations from the mean score of 
each significant constrained axis. The position in the genome and putative associated function of the selected loci were obtained using the tarakihi reference genome assembly annotation produced in Papa et al. (2021c).

\section{3}

\subsection{General bioinformatics tools}

All SAM files were converted to sorted BAM files with SAMtools sort and BAM files were indexed with SAMtools index. Alignments statistics were computed with SAMtools flagstats and BamTools v2.5.1 (Barnett et al., 2011) stats. VCF files were imported and converted to genlight objects in R with vcfR v1.12.0 (Knaus and Grünwald, 2017). dartR v1.9.6 was used for manipulations of genlight objects (e.g. population assignment, filtering of individuals and monomorphic loci). Analyses were performed on Rāpoi, the Victoria University of Wellington highperformance computer cluster. Analyses requiring R scripts were performed in R v4.02 (R Core Team, 2020) on RStudio (RStudio Team, 2020).

\section{Results}

\section{$363 \quad 3.1$ Sequencing}

364 Following quality filtering and adapter trimming, a total of 12.1 billion Illumina reads, with an 365 average length of $150 \mathrm{bp}$, were obtained from 188 individuals. The mean GC content was 44.8\%. All individual samples passed all the FastQC criteria. The number of reads per sample ranged from 17.1 million to 124.0 million (64.1 million on average) (Supplementary Figure 3A). This translated to a mean read sequencing depth per individual of $16.9 \times$, ranging from $4.5 \times$ to $32.7 \times$, with only eight individuals below $8 \times$.

\subsection{SNP datasets}

Quality filtering of variants led to a total of 7,536,950 high-quality bi-allelic SNPs with a mean depth per individual of $12.7 \times$ (Supplementary Figure 3B). The "pruned" dataset that included all scaffolds and individuals was made up of 183,443 high-quality, independently segregating SNPs. To obtain the neutral dataset, 23 individuals were discarded and the analysis was restricted to the 250 longest scaffolds (see Methods). This final neutral dataset contained 166,022 high-quality, independently segregating, neutrally evolving bi-allelic SNPs (Figure 3). The mean SNP depth per individual in that dataset was $12.0 \times(0.04 x-23 \times)$ and the number of missing sites per individual ranged from 5 to 164,506, with 151 individuals (92\% of total) missing less than 400 sites (Supplementary Figure 3C).

There was a clear difference in observed heterozygosity between tarakihi and king tarakihi specimens in the quality-filtered dataset, with an average of 0.12 and 0.06 , respectively (Supplementary Figure 3B). The GBK specimen had a heterozygosity level typical of a tarakihi. In the neutral dataset, the mean observed heterozygosity was 0.13 , ranging from 0.09 to 0.15 . The levels of heterozygosity did not significantly vary among locations but were directly related to the mean SNP depth, which in turn was correlated to the number of missing sites per individual. The relationship between heterozygosity levels and depth of coverage was especially evident in the 14 samples with a heterozygosity $<0.12$, which all had a mean depth $<7 x$.

387 In the high-quality total SNP dataset, 84,144 allelic differences were fixed between the king tarakihi 
only TBGB juveniles, Wairarapa, Tasmania, Fiordland, and Chatham Islands having more than 20.

There was only one fixed mutation between GBK and the tarakihi specimens.

\section{$392 \quad 3.3 \quad$ Linkage Disequilibrium}

393 Linkage disequilibrium in tarakihi was low overall, with mean pairwise $R^{2}$ values never exceeding 3940.2 , even between nucleotide sites less than $100 \mathrm{bp}$ apart (Figure 4). Linkage disequilibrium decay 395 was also rapid: both $R^{2}$ and mean $R^{2}$ values plotted on the distance between nucleotides always 396 reached a plateau between 500 and 1,500 bp (Figure 4). The threshold limit for the thinning step in the variant filtering pipeline was thus set to a conservative 1,500 bp. Interestingly, when the same analysis was run while including the king tarakihi specimen, the $R^{2}$ values were generally higher and more uniform along the length of the scaffolds (Supplementary Figure 4).

\section{$400 \quad 3.4 \quad$ Population structure}

401 Several AMOVAs were run on the neutral and the adaptive datasets to assess the proportion of genetic variance that could be explained by pre-assigned groupings in these datasets. Groupings of sampling locations included management areas (with or without including Tasmania) and New Zealand coasts (i.e. two groups: west coast and east coast). Overall, there was no significant genetic structure among management areas, coasts, or sampling locations when analysing the neutral dataset (Table 2). The only significant genetic differentiation $(\Phi=0.001, P=0.001)$, was detected among sample locations without any a priori broader grouping, and only when the Tasmania location was included, which means the differentiation between New Zealand and Tasmania is driving that result. Conversely, the AMOVAs based on presumably adaptive SNPs showed sample locations to always be significantly differentiated $(P \leq 0.01)$ with the percentage of explained variation ranging from $6.1 \%$ to $20.5 \%$ depending on the grouping used (Table 2), while the majority of the variation was still within individuals $(76.5 \%-93.32 \%, P \leq 0.01)$. No significant genetic structure was detected among management areas or between the west and east coasts of New Zealand in the adaptive dataset.

414 The PCA performed on the pruned dataset containing all 188 individuals showed that king tarakihi (18.KTAR) and the tarakihi from Tasmania (17.TAS) form two distinct clusters that are separate from all New Zealand tarakihi specimens (Figure 5). The differentiation between these two groups drove most of the variation of the first axis and the second axis, which explained $4.61 \%$ and $0.72 \%$ of the total variation, respectively. No structure was apparent among the New Zealand populations: sampling locations were randomly distributed on the third and fourth axes (Figure 5). Similarly, the DAPC conducted on $K$-means clustering did not infer any groups related to sampling locations among New Zealand tarakihi (Supplementary Figures $5 \& 6$ ). In both PCA and DAPC, the GBK specimen was always grouped within the tarakihi individuals and did not display any particular deviation from them, thus challenging its field identification as a king tarakihi. The PCA and DAPC conducted on the neutral dataset gave identical results, in that Tasmania was separated from New Zealand but no structure could be detected among New Zealand locations (Supplementary Figures 7 9).

427 PCA and DAPC performed on the adaptive dataset (389 SNPs) showed a genetic differentiation of remaining tarakihi in New Zealand (Figure 6, Supplementary Figure 10). Each of these groups explained most of the variation on the first, second, and third axes of the PCA, which accounted for $25.63 \%, 2.41 \%$, and $1.81 \%$ of the total variation, respectively (Supplementary Figure 10). 
The PCA and DAPC analyses were performed a second time on the adaptive dataset, but this time the Tasmania, Wairarapa, and Cape Campbell locations were discarded before the outlier analysis (see Methods), which resulted in a second adaptive dataset of 61 SNPs from 140 individuals. The DAPC discriminated three additional groups that corresponded to sampling locations (Figure 7): Upper West Coast of South Island (05.UWCSI), Hawke's Bay (12.HB), and a group from Tasman Bay/Golden Bay (03. TBGB) that also included one individual from Wellington (10.WGTN) and one from the Upper West Coast of North
(Supplementary Figure 11).

Pairwise weighted mean $F_{\text {ST }}$ computed on the neutral dataset always showed high and significant $0.0073, P \leq 0.05$ after false discovery rate correction), indicative of a clear genetic differentiation between tarakihi from Australia and New Zealand (Supplementary Figure 12). When comparing only populations from New Zealand (Figure 8 ), the $F_{\mathrm{ST}}$ values were globally low $\left(F_{\mathrm{ST}}=0-0.0022\right)$, indicating a lack of overall sub-structure. However, some of the pairwise $F_{\text {ST }}$ comparisons among locations were significant ( $P \leq 0.05$ after false discovery rate correction): in particular Wairarapa, which was significantly different to four other locations: Upper West Coast of South Island, Taranaki, East Northland, and East Cape $\left(F_{\mathrm{ST}}=0.0012-0.0021\right)$. The only other significant differentiation was between Wellington and East Northland/Hauraki Gulf $\left(F_{\mathrm{ST}}=0.0004\right)$. The dendrogram based on $F_{\text {ST }}$ separated Wairarapa from all other New Zealand locations, which were split into two further clades separating Upper West Coast of South Island, Taranaki, and East Northland from the rest of the locations.

The relatively high divergence between Tasmania and New Zealand locations was also apparent in between 0.5232 and 0.5532 . The mean pairwise $F_{\text {ST }}$ values among New Zealand samples was also higher than in the neutral dataset $\left(F_{\mathrm{ST}}=0.0251-0.1931\right)$ and all values were highly significant $(P<$ 0.01 after false discovery rate correction) (Figure 9). This was expected since the dataset was composed of outlier SNPs with the highest $F_{\mathrm{ST}}$ values only. Wairarapa and Cape Campbell were the most divergent from the rest of the locations $\left(F_{\mathrm{ST}}=0.1096-0.1931\right)$, followed by East Northland/Hauraki Gulf and Hawke's Bay $\left(F_{\mathrm{ST}}=0.0435-0.1832\right)$.

FastSTRUCTURE did not detect any significant groupings in the neutral dataset, even including samples from Tasmania: the number of populations that best explained the structure was one. No significant pattern of isolation by distance was detected among New Zealand tarakihi locations when using a matrix of least-coast distance restricted to ocean travel on the neutral dataset $(R=0.260, P=$ $0.414)$.

\subsection{Genotype-environment association analysis}

467 Out of the eight longest scaffolds, only scaffold 1 was significant for its respective RDA model $(P=$ $0.022)$. Moreover, for this model, only the first axis was significant $(P=0.01$, with $P>0.1$ for all other axes). Interpretations of the results were thus restricted to axis 1 of the RDA of scaffold 1 . The adjusted $R^{2}$ of the model was 0.05 , and the variance inflation factors (vegan v2.5.7 function vif.cca) of the six predictor variables were all below 1.6, indicating that there was no multicollinearity among them. The projection of the SNPs, samples, and environmental variables on the first two axes shows that the sampling locations were effectively discriminated (Figure 10). Moreover, all samples projected in negative values of axis 1 were either from North Island or TBGB. Conversely, samples projected in positive values of axis 1 included all South Islands locations 
(except TBGB), all samples from Wairarapa and Chatham Islands, and a few samples from East Cape and Hawke's Bay close to the center.

Selection of outliers on the end tails of the loading distribution resulted in the identification of 55 candidate loci for local adaptation (Supplementary Table 3). Out of these 55 loci, 47 most strongly correlated with mean temperature at mean depth, five with mean primary production at minimum depth, two with mean iron concentration at the sea surface, and one with salinity range at mean depth. Thirty-two were located inside gene coding regions (with two pairs of loci being located in the same genes, mindy3 and LOC111664994), eight were located in simple repeat regions, 14 in unannotated regions (most of them surrounded by highly-repetitive regions), and one in an unannotated, putatively transcripted region. A search of the Gene Ontology terms available for the same genes in zebrafish (Danio rerio) (Supplementary Table 4) showed that the most common associated GO terms were integral components of membranes (in four genes: transmembrane protein 67, glycoprotein endo-alpha-1,2-mannosidase-like protein, thrombospondin type-1 domaincontaining protein $7 \mathrm{~A}$, and chondroitin sulfate proteoglycan 5a) and cilium assembly (in three genes: transmembrane protein 67, inositol polyphosphate-5-phosphatase B, and Zgc:171454 protein).

\section{Discussion}

This study investigated the neutral and adaptive stock structure on an expansive marine species that supports an important inshore commercial fishery. To detect environmental drivers associated with genetic structure, this study also applied gene-environment association analyses to gain insights into the selective forces acting on this species.

\section{6}

\subsection{Genetic diversity}

Tarakihi in New Zealand and Tasmania displayed similar levels of heterozygosity across their range (Supplementary Figure 3). The differences in heterozygosity observed in some individuals did not depend on the location but rather the sequencing depth, which means that a proportion of the genetic variation might not have been detected in the 14 lower coverage individuals. A plateau in heterozygosity seems to be reached when the mean coverage depth was $>7-8 x$, which indicates that the totality of the relevant genetic variation that could be captured at this level has been captured. The slightly higher mean heterozygosity for the neutral dataset could indicate that some of the filtered out outlier loci had a higher proportion of homozygotes, with some alleles possibly restricted to only a few populations in the dataset. A small fraction of less variable sites might also have been filtered out during the pruning step, due to deviations from Hardy-Weinberg and/or linkage equilibrium. The observed heterozygosity per individual is simply calculated as the proportion of heterozygous loci for that individual against the background of loci that are polymorphic in the dataset. It is difficult to say if this value is high in absolute terms. Comparison with results reported from other genome-wide SNP studies are not relevant, because contrary to e.g. mitochondrial markers, the observed loci are not necessarily directly comparable since the proportion of loci that are invariant across all individuals in each dataset is typically unknown (Gruber et al., 2021). A similar study using wholegenome resequencing in the Australasian snapper (Chrysophrys auratus) in New Zealand found a higher average heterozygosity of c. 0.20 for neutral loci (Oosting, 2021), while the snapper populations in New Zealand are smaller with supposedly lower connectivity among stocks than tarakihi.

517 Based on the same SNP dataset, it was clear that the heterozygosity in king tarakihi is lower than that 518 of tarakihi (Ho $=0.06$, Supplementary Figure 3B). This is expected from a population with a much 
and current population size for this species (Papa et al., 2021a). However, since the reference genome was a tarakihi, it is possible that the heterozygosity values of the king tarakihi specimens were underestimated due to species-specific genome mapping success. This clear cut difference in heterozygosity was strong evidence that GBK had been misidentified when captured on the field, with a value corresponding to tarakihi and not king tarakihi ( $\mathrm{Ho}=0.12$, Supplementary Figure 3B). The high number of fixed mutations between tarakihi and king tarakihi $(84,144$ fixed allelic differences) is additional strong evidence of the separate status of these two organisms (Smith et al., 1996, 2008; Burridge, 1999; Papa et al., 2021a). As a comparison, there are only three fixed allelic differences between tarakihi from Tasmania and New Zealand. These fixed mutational differences could be used as the basis for an SNP assay to differentiate tarakihi from king tarakihi in the field. The number of fixed SNPs among tarakihi in New Zealand locations was very low overall. Even for the Chatham Islands, where the number of mean fixed alleles with all New Zealand populations was 145, there were only five fixed alleles compared to the rest of New Zealand. This result could be due to undersampling because of the very low number of samples from Chatham Islands $(n=2)$.

\section{$534 \quad 4.2 \quad$ Linkage disequilibrium}

535 Linkage disequilibrium values were overall low in tarakihi, with mean $R^{2}$ values never exceeding 0.2 (Figure 4). The decay rate was also very fast, with a plateau reached between 500 and 1,500 bp in all scaffolds. Fast decay of linkage disequilibrium is expected to be common for marine fishes, due to them maintaining very high effective population sizes over long periods of time (Hemmer-Hansen et al., 2014). Indeed, tarakihi effective population size has been historically very high, with a current estimation of about 100 million individuals (Papa et al., 2021a). However, linkage disequilibrium can also be impacted by admixture, mutation rate, founder effect, inbreeding and selection. Linkage disequilibrium values for genome-wide datasets are seldom available for marine organisms, but the results reported here are on par with values reported for European eel (Anguilla anguilla, complete LD below $10 \mathrm{~kb}$ ) and Atlantic cod (Gadus morhua, complete LD decay below 10 centimorgans) by Hemmer-Hansen et al. (2014). This is also consistent with results reported from Australasian snapper, with a complete LD decay at 1,500 bp (Oosting, 2021).

Including the king tarakihi specimens in linkage disequilibrium analyses resulted in a slightly steeper disequilibrium decay and higher, more uniform $R^{2}$ values along the scaffolds (Supplementary Figure 4). This could be indicative of an overall higher linkage disequilibrium in king tarakihi, due to a combination of small and recent stable population size. This could also indicate the presence of structural differences in the king tarakihi genome that would result in the physical distance between the bases being both underestimated and overestimated when aligned to the tarakihi genome, resulting in the detection of high linkage disequilibrium between relatively distant nucleotides (and inversely). Comparing results by aligning the king tarakihi SNPs to a contiguous king tarakihi genome assembly would be a good way to test for this.

\subsection{Neutral genetic differentiation with king tarakihi and Australia}

557 The strong genetic differentiation between tarakihi and king tarakihi is now well established (e.g. taxonomic description as a separate species (tentatively N. rex) (Smith et al., 1996; Roberts et al., 2015, 2020; Papa et al., 2021a). However, king tarakihi is still currently reported and managed as 561 part of TAR1.

562 Evidence for a partial lack of connectivity between Tasmanian and New Zealand tarakihi is very 563 strongly supported by our results. A significant level of genetic divergence between these two areas 
$(P \leq 0.01)$ was detected by both AMOVA and pairwise $F_{\mathrm{ST}}$ analyses (Table 2, Supplementary Figure 12). Tasmanian individuals were always clustered together and separated from the New Zealand samples. These results support similar findings of trans-Tasman differentiation for tarakihi based on various genetic markers (Richardson, 1982; Elliott and Ward, 1994; Grewe et al., 1994), which microsatellites likely failed to detect (Burridge and Smolenski, 2003). It can be reasonably extrapolated that this genetic divergence to New Zealand would also be found in samples analysed from other locations in the Australian range, meaning there are likely two separate reproductive stocks, one in Australia and one in New Zealand. It would be useful to compare samples taken from additional locations in Australia: some genetic studies have reported a genetic distinction between fish stocks from west and east Australia even when the gene flow between Australia and New Zealand was putatively high. This is the case for e.g. gemfish (Rexea solandri) (Colgan and Paxton, 1997), kingfish (Seriola lalandi), (Nugroho et al., 2001; Miller et al., 2011), and mako shark (Isurus oxyrinchus) (Corrigan et al., 2018).

\subsection{Neutral genetic structure in New Zealand tarakihi}

The analysis of 166,022 neutral genome-wide SNPs conducted in this study indicates that tarakihi have a panmictic genetic population structure throughout their distribution around mainland New Zealand. This may also include the Chatham Islands, although the number of samples for this location is too low to test this. No obvious genetic structure related to sampling locations or management areas were detected by any of the methods used (AMOVA, PCA, DAPC, and FastSTRUCTURE) and no significant isolation by distance was detected either. The only significant genetic differences detected were through the pairwise $F_{\text {ST }}$ between Wairarapa (south-east of North Island) and four other locations: Upper West Coast South Island, Taranaki, East Northland, and East Cape (Figure 8).

This result is difficult to interpret in terms of geographic stock structure since these four locations are situated at several distant areas around New Zealand and are separated from the Wairarapa by other non-significantly divergent locations (e.g. TBGB, Hawke's Bay and Hauraki Gulf) (Figure 2). The divergence with East Cape and East Northland could be indicative of a complex, fine-scale migration pattern northward along the east coast of North Island, which would be partially concordant with the results from the mitochondrial study (Papa et al., 2021a). The divergence of Wairarapa compared to Taranaki and Upper West Coast of South Island could be due to a partial lack of connectivity between Wairarapa and the west coast through Cook Strait. However, this seems unlikely since no significant genetic divergence was detected between Wairarapa and Upper West Coast of North Island or Lower West Coast of South Island. It is worth noting that the genetic divergence found between Wairarapa and these four locations, while still significant after fdr correction, is very low $\left(F_{\mathrm{ST}}=0.0012-0.0021\right)$. Moreover, while all Wairarapa samples have been sequenced at a good depth and have a "normal" (i.e. expected) level of heterozygosity (Supplementary Figure 3), and therefore the relevant individual genetic variation can be reasonably thought to have been captured, the number of individuals from this location is the lowest included in the neutral dataset ( $n=5$ individuals only). The detected genetic divergence might thus be an artefact due to the low number of samples for this location, causing individuals to have a high proportion of fixed allelic differences because the totality of the allelic variation in that location has not been sampled. However, simulation studies have shown that genetic differentiation measured by $F_{\mathrm{ST}}$ can still be accurately estimated in populations as small as $n=4-6$ when the number of SNPs is above thousands (Willing et al., 2012). No comparison 
609

610

611

612

613

614

615

616

This overall lack of population genetic structure for tarakihi around New Zealand is concordant with results from Papa et al. (2021a) where no evidence of genetic structure was detected for the overall New Zealand area, including Chatham Islands. These results appear to consistently suggest that there is one panmictic tarakihi stock in New Zealand, with very high spatial connectivity and no spatial reproductive isolation. This finding is concordant with the characteristics of a species with a high capacity for dispersal, reproduction output, and effective population size, and would also explain the failure to detect any genetic structure among Australian stocks either, despite numerous attempts (Richardson, 1982; Elliott and Ward, 1994; Grewe et al., 1994; Burridge and Smolenski, 2003).

\subsection{Adaptive genetic structure}

The acquisition of a first and then a second set of putatively adaptive outlier SNPs resulted in the detection of fine-scale genetic structure that was not observed in the neutral tarakihi genetic dataset (Figures 6\&7, Figure 9). Interestingly, the presumably adaptive genetic variation detected always discriminated groups at the sampling location level, rather than clustering groups at a broader geographic level (e.g. management area, coast, island). The first set of 389 presumably adaptive SNPs discriminated Tasmania from New Zealand, meaning that the genetic divergence observed between these two stocks is likely due to both physical isolation and local adaptation. They also discriminated Wairarapa and Cape Campbell from all other New Zealand locations (Figure 6). While Wairarapa and Cape Campbell are geographically close (south-east of North Island and north-east of South Island, Figure 2) it is not obvious if they should be considered together as one or two different adaptive stocks separated from New Zealand: although they formed two different clusters on the PCA and DAPC (Figure $6 \&$ Supplementary Figure 10), most of the variation of both groups were on the axis 2 of the DAPC (Figure 6) and on both the axes 2 and 3 of the PCA (Supplementary Figure $10)$. Moreover, the dendrogram inferred on the pairwise $F_{\mathrm{ST}}$ clustered the locations together as outgroup of the rest of New Zealand, even though the $F_{\mathrm{ST}}$ value between them $\left(F_{\mathrm{ST}}=0.1762\right)$ was one of the highest among all pairwise locations (Figure 9).

Excluding Tasmania, Wairarapa and Cape Campbell improved the statistical power of the outlier method. With this second dataset of 61 putative adaptive SNPs, the $K$-mean clustering analysis was able to also discriminate Upper West Coast South Island, Hawke's Bay, and TBGB without any $a$ priori grouping. Interestingly, although TBGB and Upper West Coast South Island are both on the west coast of South Island, these three putatively adaptive stocks seem to be actually separated from each other and from the rest of New Zealand (Figure 7).

Wairarapa, Cape Campbell, Hawke's Bay, Upper West Coast South Island, and TBGB were found to be genetically divergent from each other and from all of the remaining New Zealand locations, which includes sites as far apart as East Northland, Christchurch, and lower West Coast South Island. If these outlier-based stocks are indeed adaptive, this would indicate that there is no broad separation of adaptive genetic stocks around New Zealand, but rather that the tarakihi population displays some very fine-scale local adaptation to specific areas around New Zealand, that are not, at first look, directly linked to e.g. temperature or depth. This adaptive genetic variation could be school-specific, i.e. representative of genetically adapted small groups, rather than due to large-scale environmental factors. Interestingly, Gauldie \& Johnston (1980) also found genetic differentiation between lower and upper west coast of South Island, although the sampling locations were a bit further apart (Jacksons Bay and Westport). While they also detected a genetic break between TBGB and Cape Campbell, the former was thought to be part of a broader western genetic stock including Upper West Coast South Island and Taranaki and the latter an eastern one including Christchurch and East Cape. 
Given these results and the small sample size of some of these locations (especially Wairarapa, $n=5$ and Hawke's Bay, $n=7$ ), it is legitimate to question if these observations are statistical artefacts. The outlier method used here is particularly suited to detect loci under heterogeneous selection and local adaptation (Whitlock and Lotterhos, 2015). Although the two SNP datasets obtained with this method are only putatively adaptive, they are very strong candidates for adaptation because the parameters used to detect them were quite stringent: only loci with $q<0.05$ and $\mathrm{He}>0.1$ were retained, the first to greatly minimize the risk of false positives and the second to discard lowfrequency alleles that do not fit the neutral $F_{\mathrm{ST}}$ distribution used to find outliers. Moreover, the OutFLANK method does not rely on an a priori population model, and is very robust against false positives: in fact, when the number of individuals per location is low, OutFLANK tends to lose power and will produce more false negatives instead of false positives (Whitlock and Lotterhos, 2015). Thus, it is likely that the adaptive divergence observed is biologically relevant and not an artefact due to the small sample size of some locations.

\subsection{Temperature-associated selective cline}

667 Contrary to the PCA and DAPC performed on the neutral and outlier-based adaptive SNP datasets, 668 the RDA of the reduced quality-filtered SNP dataset was very effective at discriminating samples based on localities (Figure 10). Given that only the first axis of the RDA on scaffold 1 was significant, and that 47 out of $55(85 \%)$ of the candidate environmentally-adapted loci were most strongly correlated with mean temperature at mean depth, the variation observed on axis 1 appears to be driven by adaptation to temperature, or to any other environmental variable strongly correlated with temperature (e.g. salinity, $\mathrm{pH}$, dissolved oxygen concentration). Moreover, the samples were ordinated following a latitudinal gradient, which is directly related to temperature on the continental shelf, where tarakihi occur (Supplementary Figure 14). Only TBGB and Wairarapa are not projected with, respectively, the South and the North Island (Figure 10). This is explained by the fact that TBGB is actually situated further north than Wairarapa. This means that the observed genetic variation is directly related to temperature (and thus latitude) rather than a theoretical differentiation between the North and the South Island driven by e.g. a dispersal barrier in Cook Strait. This was verified with a linear regression analysis that showed that there was a significant correlation between the ordination on the RDA axis 1 and both the mean temperature and the latitude at sampling locations (Pearson $R^{2}=-0.65, P<0.001$ for both variables, Supplementary Figure 15).

\section{$683 \quad 4.7 \quad$ Fisheries management implications}

684 It is now well established that the Quota Management Area boundaries for tarakihi in New Zealand 685 do not match the biological stock boundaries (Langley, 2018; Fisheries New Zealand, 2021). The Chatham Islands are usually considered a separate stock from the North and South Island because these two areas are geographically separated by deep water which is not usually inhabited by adult tarakihi (Morrison et al., 2014; Fisheries New Zealand, 2021). Although the main islands are split into several management areas (Figure 2), they are not thought to be accurate reflections of the reproductive stock boundaries. Both North and South Islands have been generally considered as one single stock due to the high capacity of post-larvae and adults for dispersal and the lack of evidence of genetic isolation (Morrison et al., 2014; Fisheries New Zealand, 2021). Some specimens tagged in the Kaikoura area on the east coast of South Island have been recaptured on the west coast of North Island (Hanchet and Field, 2001), suggesting that there is at least some level of connectivity between the west and east coasts. Recent studies on trends in age and size structure in TAR1, TAR2 and TAR3 found evidence that the east coast of North and South Island could be one continuous stock (McKenzie et al., 2017; Langley, 2018). The Canterbury Bight/Pegasus Bay area (east of South 
698

699

700

701

702

703

704

705

706

707

708

709

710

711

712

713

714

715

716

717

718

719

720

721

722

723

724

725

726

727

728

729

730

731

732

733

734

735

736

737

738

739

740

741

742

Island) seems to be the main nursery area for juveniles of the entire eastern stock. At the onset of maturity, some of the adult fish migrate northward along the east coast to East Cape, then up to the east Northland area. This scenario is backed up by the higher proportion of juveniles in Canterbury Bight/Pegasus Bay and the observed increase in the proportion of older fish from TAR 2, Bay of Plenty and east Northland (Langley, 2018). Subsequent studies have found a similar pattern for the west coast of New Zealand (Fisheries New Zealand, 2021). Observations about the relative strength of individual year classes and growth rates of older fish seem to indicate that Tasman Bay/Golden Bay (TBGB) could act as a nursery area for the entire west coast, which would constitute a single separated stock from the east coast, with a possible lack of connectivity between the upper west coast of North Island and the East Northland fisheries (Fisheries New Zealand, 2021).

There is thus strong preliminary evidence that tarakihi are constituted of two main stocks in New Zealand, however, the present analysis of neutral genomic variation does not support this hypothesis, since no genetic divergence was detected between the west and the east coast, for both islands, even when grouping them using AMOVA. Moreover, the weak genetic divergence that was detected between the west and east coast of the South Island using mitochondrial data (Papa et al., 2021a) could not be corroborated in this study. A similar situation occurred with the Australian stocks: the observation of no genetic structure in Australia reported by Burridge \& Smolenski (2003) was in contrast with two studies that detected three stocks within the south-east of Australia based on otolith microchemistry (Thresher et al., 1994) and larval advection (Bruce, 2001).

When a test for genetic differentiation rejects the model of panmixia, it can usually be used with confidence as a biologically meaningful finding. However, it is more difficult to firmly conclude that stocks are demographically coupled whenever the test fails to reject panmixia (Waples et al., 2008). The demographic structure described by Langley (2018) might not be a reasonable conclusion from the present population genomic analyses because there may be a high enough level of connectivity between stocks to sufficiently homogenise genetic variation, but not enough to provide demographic coupling between areas. Some level of migration between the west and east coasts is highly likely, based e.g. on tagging studies (Hanchet and Field, 2001). Only a few migrants per generation are needed to homogenise most genetic loci, and a large effective population size reduces the speed at which differentiation occurs through the action of genetic drift. Furthermore, any demographic separation between stocks might have arisen too recently for a parallel pattern to also be seen in a test for genetic differentiation. The population genomics findings do not necessarily contradict the findings reported from age and size data. There is still the possibility that there is a western and an eastern stock that may only be partially reproductively isolated, and that some small level of gene flow still occurs and is enough to homogenise genetic variation.

The outlier-based, presumably adaptive differentiation reported here is unlikely to be directly useful for the delineation of fisheries management stocks at this stage, since the genetic variation appears to be highly localized and not reflecting any known broader stock boundaries (Figure 2). However, the genotype-environment association analysis hints at the possibility of a North-South adaptive cline in the stock related to water temperature (Figure 10, Supplementary Figure 15). The pattern of genetic variation found at these loci should be monitored through time to test whether changes in water temperatures have influenced the distribution of alleles over time. The tarakihi population may show an adaptive response to future climate and sea temperature changes, but the consequences of this for the resilience of the fishery is largely unknown.

While the level of population genomic resolution found in this study was high, the number of individuals sampled is relatively low, especially in some locations because very few samples could 
be obtained. Simulation studies have shown that genetic structure can sometimes be detected by only sampling a few individuals per population (c. 8-10) as long as the genome-wide SNP density is high (Jeffries et al., 2016; Nazareno et al., 2017). However, the power of clustering methods (i.e. K-means clustering for DAPC) can drop sharply when a small number of individuals is used (Waples and Gaggiotti, 2006), and given the high effective population size and the high level of gene flow in New Zealand tarakihi, a much larger DNA sampling and sequencing campaign might be necessary to provide fisheries managers with a definitive answer of the presence or absence of genetic stock structure among tarakihi in New Zealand.

\section{Conclusion}

752

753

754

755

756

757

758

759

760

This study is the first population genomics analysis of tarakihi (Nemadactylus macropterus) and one of the very first genome-wide analyses of a New Zealand marine species. The acquisition and subsequent filtering of a large SNP dataset allowed for the detection of a low but highly significant genetic differentiation between Tasmania (and thus putatively the whole of Australia) and New Zealand. No neutral genomic structure was detected among New Zealand locations, which means the genomic data did not support the hypothesis of two separate reproductive stocks on the west and east coast of New Zealand. A latitudinal adaptive cline strongly correlated to water temperature was found. The associated loci are strong candidates for further investigation to identify potential functional adaptive role.

Tarakihi is a commercially important fishery but it has been reported as declining. Implementation of routine genomic sampling could enhance spatial and temporal genomic resolution. This could be implemented using a long-term, standardised, well-archived genetic-based tagging program (Mace et al., 2020; Papa et al., 2021b). Integrating results obtained from genetic-tagging data with life history information and results obtained from other fisheries assessment methods will prove extremely valuable for the long-term sustainable use of this important fishery species.

\section{Conflict of Interest}

The authors declare that the research was conducted in the absence of any commercial or financial relationships that could be construed as a potential conflict of interest.

\section{$7 \quad$ CRediT authorship contribution statement}

YP: Conceptualization, Methodology, Software, Validation, Formal analysis, Investigation,

772 Resources, Data Curation, Writing - Original Draft, Writing - Review \& Editing, Visualization. MM:

773 Resources, Writing - Review \& Editing, Supervision, Funding acquisition. MW: Writing - Review \&

774 Editing, Supervision. PR: Conceptualization, Resources, Writing - Review \& Editing, Supervision,

775 Project administration, Funding acquisition.

\section{$\begin{array}{lll}776 & 8 & \text { Funding }\end{array}$}

777 This work was supported by a Victoria University of Wellington Doctoral Scholarship to Yvan Papa, 778 and as part of the National Institute of Water and Atmospheric Research project "Juvenile Fish 779 Habitat Bottlenecks" funded by the New Zealand Ministry of Business, Innovation and Employment 780 Endeavour Fund Research Programme (CO1X1618).

\section{Acknowledgments}


782

783

784

785

786

787

788

789

790

791

792

793

794

795

796

797

798

799

800

801

802

803

804

805

806

807

808

809

810

811

812

813

814

815

816

817

818

819

820

821

We are grateful to the following people and companies who contributed to this study. Collection of the tarakihi and king tarakihi specimens from phase 1 (2017-2018) was supervised by Cameron Walsh (Stock Monitoring Services Limited). Specimens were collected by fishing companies (Gisborne Fisheries, Star Fish Supply, Egmont Seafoods, Moana New Zealand, Hawke's Bay Seafoods, United Fisheries, Talley's Seafood, and Wellington Trawling) and Peter Young (Cruise Fiordland). Alex Halliwell (Victoria University of Wellington) provided assistance for the tissue collections and DNA extractions. The majority of samples from phase 2 (2019-2020) were collected by NIWA staff including Jeremy McKenzie, Dan MacGibbon, Helena Armiger, Jade Arnold, and Caoimhghin Ó Maolagáin. Samples from Australia were collected by Anne-Marie Hegarty and Matt Taylor (New South Wales Department of Primary Industries). Additional tarakihi tissue samples were collected by Tom Oosting (Victoria University of Wellington) at Gisborne Tatapouri Sports Fishing Club and Hawke's Bay Sports Fishing Club fishing competitions. We are grateful to Alison Wilson for providing editorial feedback.

\section{References}

Aljanabi, S. M., and Martinez, I. (1997). Universal and rapid salt-extraction of high quality genomic DNA for PCR- based techniques. Nucleic Acids Res. 25, 4692-4693. doi:10.1093/nar/25.22.4692.

Allendorf, F. W., Hohenlohe, P. A., and Luikart, G. (2010). Genomics and the future of conservation genetics. Nat. Rev. Genet. 11, 697-709. doi:10.1038/nrg2844.

Andrews, S. (2018). FastQC: A quality control tool for high through-put sequence data. Available at: http://www.bioinformatics.babraham.ac.uk/projects/fastqc [Accessed January 19, 2021].

Annala, J. H. (1987). The biology and fishery of tarakihi, Nemadactylus macropterus, in New Zealand waters. eds. S. J. Baird and G. G. Baird Wellington, New Zealand: New Zealand Ministry of Agriculture and Fisheries. Available at: http://docs.niwa.co.nz/library/public/FRDop51.pdf [Accessed November 22, 2017].

Assis, J., Tyberghein, L., Bosch, S., Verbruggen, H., Serrão, E. A., De Clerck, O., et al. (2018). BioORACLE v2.0: Extending marine data layers for bioclimatic modelling. Glob. Ecol. Biogeogr. 27, 277-284. doi:10.1111/geb.12693.

Attard, C. R. M., Beheregaray, L. B., Sandoval-Castillo, J., Jenner, K. C. S., Gill, P. C., Jenner, M.N. M., et al. (2018). From conservation genetics to conservation genomics: a genome-wide assessment of blue whales (Balaenoptera musculus) in Australian feeding aggregations. R. Soc. Open Sci. 5, 170925. doi:10.1098/rsos.170925.

Barnett, D. W., Garrison, E. K., Quinlan, A. R., Stromberg, M. P., and Marth, G. T. (2011). BamTools: a C++ API and toolkit for analyzing and managing BAM files. Bioinformatics 27, 1691-1692. doi:10.1093/bioinformatics/btr174.

Beddington, J. R., Agnew, D. J., and Clark, C. W. (2007). Current problems in the management of marine fisheries. Science 316, 1713-1716. doi:10.1126/science.1137362.

Begg, G. A., Friedland, K. D., and Pearce, J. B. (1999). Stock identification and its role in stock assessment and fisheries management: an overview. Fish. Res. 43, 1-8. doi:10.1016/S01657836(99)00062-4. 
822

823

824

825

826

827

828

829

830

831

832

833

834

835

836

837

838

839

840

841

842

843

844

845

846

847

848

849

850

851

852

853

854

855

856

857

858

Benestan, L. (2019). "Population genomics applied to fishery management and conservation," in Population Genomics: Marine Organisms, eds. M. Oleksiak and O. Rajora (Cham: Springer), 399-421. doi:10.1007/13836_2019_66.

Benestan, L., Gosselin, T., Perrier, C., Sainte-Marie, B., Rochette, R., and Bernatchez, L. (2015). RAD genotyping reveals fine-scale genetic structuring and provides powerful population assignment in a widely distributed marine species, the American lobster (Homarus americanus). Mol. Ecol. 24, 3299-3315. doi:10.1111/mec.13245.

Benestan, L., Quinn, B. K., Maaroufi, H., Laporte, M., Clark, F. K., Greenwood, S. J., et al. (2016). Seascape genomics provides evidence for thermal adaptation and current-mediated population structure in American lobster (Homarus americanus). Mol. Ecol. 25, 5073-5092. doi:10.1111/mec.13811.

Benjamini, Y., and Hochberg, Y. (1995). Controlling the false discovery rate: a practical and powerful approach to multiple testing. J. R. Stat. Soc. Ser. B 57, 289-300. doi:10.1111/j.25176161.1995.tb02031.x.

Bernatchez, L., Wellenreuther, M., Araneda, C., Ashton, D. T., Barth, J. M. I., Beacham, T. D., et al. (2017). Harnessing the power of genomics to secure the future of seafood. Trends Ecol. Evol. 32, 665-680. doi:10.1016/j.tree.2017.06.010.

Bolger, A. M., Lohse, M., and Usadel, B. (2014). Trimmomatic: a flexible trimmer for Illumina sequence data. Bioinformatics 30, 2114-2120. doi:10.1093/bioinformatics/btu170.

Bosch, S. (2020). sdmpredictors: Species Distribution Modelling Predictor Datasets. Available at: https://cran.r-project.org/package=sdmpredictors.

Broad Institute (2019). Picard toolkit. Broad Institute, GitHub Repos. Available at: http://broadinstitute.github.io/picard/ [Accessed December 6, 2018].

Bruce, B. (2001). Influence of mesoscale oceanographic processes on larval distribution and stock structure in jackass morwong (Nemadactylus macropterus: Cheilodactylidae). ICES J. Mar. Sci. 58, 1072-1080. doi:10.1006/jmsc.2001.1099.

Burridge, C. P. (1999). Molecular phylogeny of Nemadactylus and Acantholatris (Perciformes: Cirrhitoidea: Cheilodactylidae), with implications for taxonomy and biogeography. Mol. Phylogenet. Evol. 13, 93-109. doi:10.1006/mpev.1999.0622.

Burridge, C. P., and Smolenski, A. J. (2003). Lack of genetic divergence found with microsatellite DNA markers in the tarakihi Nemadactylus macropterus. New Zeal. J. Mar. Freshw. Res. 37, 223-230. doi:10.1080/00288330.2003.9517160.

Cadrin, S. X. (2020). Defining spatial structure for fishery stock assessment. Fish. Res. 221, 105397. doi:10.1016/j.fishres.2019.105397.

Cadrin, S. X., Kerr, L. A., and Mariani, S. (2014). "Stock identification methods: an overview," in Stock Identification Methods : Applications in Fishery Science, eds. S. X. Cadrin, L. A. Kerr, and S. Mariani (San Diego, CA: Academic Press), 1-5. 
859

860

861

862

863

864

865

866

867

868

869

870

871

872

873

874

875

876

877

878

879

880

881

882

883

884

885

886

887

888

889

890

891

892

893

894

895

896

Carvalho, G. R., and Hauser, L. (1994). Molecular genetics and the stock concept in fisheries. Rev. Fish Biol. Fish. 4, 326-350. doi:10.1007/BF00042908.

Chang, C. C., Chow, C. C., Tellier, L. C. A. M., Vattikuti, S., Purcell, S. M., and Lee, J. J. (2015). Second-generation PLINK: rising to the challenge of larger and richer datasets. Gigascience 4, 7. doi:10.1186/s13742-015-0047-8.

Cheng, S. H., Gold, M., Rodriguez, N., and Barber, P. H. (2021). Genome-wide SNPs reveal complex fine scale population structure in the California market squid fishery (Doryteuthis opalescens). Conserv. Genet. 22, 97-110. doi:10.1007/s10592-020-01321-2.

Colgan, D. J., and Paxton, J. R. (1997). Biochemical genetics and recognition of a western stock of the common gemfish, Rexea solandri (Scombroidea: Gempylidae), in Australia. Mar. Freshw. Res. 48, 103. doi:10.1071/MF96048.

Corrigan, S., Lowther, A. D., Beheregaray, L. B., Bruce, B. D., Cliff, G., Duffy, C. A., et al. (2018). Population connectivity of the highly migratory shortfin mako (Isurus oxyrinchus Rafinesque 1810) and implications for management in the Southern Hemisphere. Front. Ecol. Evol. 6, 1-15. doi:10.3389/fevo.2018.00187.

Danecek, P., Auton, A., Abecasis, G., Albers, C. A., Banks, E., DePristo, M. A., et al. (2011). The variant call format and VCFtools. Bioinformatics 27, 2156-2158. doi:10.1093/bioinformatics/btr330.

Dormann, C. F., Elith, J., Bacher, S., Buchmann, C., Carl, G., Carré, G., et al. (2013). Collinearity: a review of methods to deal with it and a simulation study evaluating their performance. Ecography (Cop.). 36, 27-46. doi:10.1111/j.1600-0587.2012.07348.x.

Dray, S., and Dufour, A.-B. (2007). The ade4 package: implementing the duality diagram for ecologists. J. Stat. Softw. 22, 1-20. doi:10.18637/jss.v022.i04.

Elliott, N. G., and Ward, R. D. (1994). Enzyme variation in jackass morwong, Nemadactylus macropterus (Schneider, 1801) (Teleostei: Cheilodactylidae), from Australian and New Zealand waters. Mar. Freshw. Res. 45, 51-67. doi:10.1071/MF9940051.

Ewels, P., Magnusson, M., Lundin, S., and Käller, M. (2016). MultiQC: summarize analysis results for multiple tools and samples in a single report. Bioinformatics 32, 3047-3048. doi:10.1093/bioinformatics/btw354.

Fisheries New Zealand (2021). Fisheries Assessment Plenary: Stock Assessment and Stock Status Volume 3: Pipi to Yellow-eyed Mullet. Wellington, New Zealand: Ministry for Primary Industries.

Forester, B. R., Jones, M. R., Joost, S., Landguth, E. L., and Lasky, J. R. (2016). Detecting spatial genetic signatures of local adaptation in heterogeneous landscapes. Mol. Ecol. 25, 104-120. doi:10.1111/mec.13476.

Forester, B. R., Lasky, J. R., Wagner, H. H., and Urban, D. L. (2018). Comparing methods for detecting multilocus adaptation with multivariate genotype-environment associations. Mol. Ecol. 27, 2215-2233. doi:10.1111/mec.14584. 
897

898

899

900

901

902

903

904

905

906

907

908

909

910

911

912

913

914

915

916

917

918

919

920

921

922

923

924

925

926

927

928

929

930

931

932

933

934

Gauldie, R. W., and Johnston, A. J. (1980). The geographical distribution of phosphoglucomutase and glucose phosphate isomerase alleles of some New Zealand fishes. Comp. Biochem. Physiol. Part B Comp. Biochem. 66, 171-183. doi:10.1016/0305-0491(80)90051-6.

Grewe, P. M., Smolenski, A. J., and Ward, R. D. (1994). Mitochondrial DNA Diversity in Jackass Morwong ( Nemadactylus macropterus : Teleostei) from Australian and New Zealand Waters. Can. J. Fish. Aquat. Sci. 51, 1101-1109. doi:10.1139/f94-109.

Gruber, B., Georges, A., Mijangos, J. L., Unmack, P. J., Berry, O., Clark, L. V., et al. (2021). Package 'dartR': Importing and analysing SNP and silicodart data generated by genome-wide restriction fragment analysis. Available at: https://cran.rproject.org/web/packages/dartR/dartR.pdf [Accessed August 26, 2021].

Gruber, B., Unmack, P. J., Berry, O. F., and Georges, A. (2018). DARTR: An R package to facilitate analysis of SNP data generated from reduced representation genome sequencing. Mol. Ecol. Resour. 18, 691-699. doi:10.1111/1755-0998.12745.

Hanchet, S. M., and Field, K. (2001). Review of current and historical data for tarakihi (Nemadactylus macropterus) fishstocks TAR 1,2,3, and 7, and recommendations for future monitoring. Wellington, New Zealand: Ministry of Fisheries. Available at: http://docs.niwa.co.nz/library/public/FAR2001_59.pdf [Accessed November 28, 2017].

Harrell, F. E. (2021). Hmisc: Harrell Miscellaneous. Available at: https://cran.rproject.org/package $=$ Hmisc.

Hemmer-Hansen, J., Therkildsen, N. O., and Pujolar, J. M. (2014). Population Genomics of Marine Fishes: Next-Generation Prospects and Challenges. Biol. Bull. 227, 117-132. doi:10.1086/BBLv227n2p117.

Hijmans, R. J. (2019). raster: Geographic Data Analysis and Modeling. Available at: https://cran.rproject.org/package=raster.

Hoey, J. A., and Pinsky, M. L. (2018). Genomic signatures of environmental selection despite nearpanmixia in summer flounder. Evol. Appl. 11, 1732-1747. doi:10.1111/eva.12676.

Jeffries, D. L., Copp, G. H., Lawson Handley, L., Olsén, K. H., Sayer, C. D., and Hänfling, B. (2016). Comparing RADseq and microsatellites to infer complex phylogeographic patterns, an empirical perspective in the Crucian carp, Carassius carassius, L. Mol. Ecol. 25, 2997-3018. doi:10.1111/mec.13613.

Jombart, T. (2008). adegenet: a R package for the multivariate analysis of genetic markers. Bioinformatics 24, 1403-1405. doi:10.1093/bioinformatics/btn129.

Kamvar, Z. N., Tabima, J. F., and Grünwald, N. J. (2014). Poppr : an R package for genetic analysis of populations with clonal, partially clonal, and/or sexual reproduction. PeerJ 2, e281. doi:10.7717/peerj. 281 .

Kaschner, K., Kesner-Reyes, K., Garilao, C., Segschneider, J., Rius-Barile, J., Rees, T., et al. (2019). AquaMaps: Predicted range maps for aquatic species version 10/2019. Available at: www.aquamaps.org [Accessed February 17, 2021]. 
935

936

937

938

939

940

941

942

943

944

945

946

947

948

949

950

951

952

953

954

955

956

957

958

959

960

961

962

963

964

965

966

967

968

969

970

971

Knaus, B. J., and Grünwald, N. J. (2017). VCFR: a package to manipulate and visualize variant call format data in R. Mol. Ecol. Resour. 17, 44-53. doi:10.1111/1755-0998.12549.

Kolde, R. (2019). pheatmap: Pretty Heatmaps. R package version 1.0.12. Available at: https://cran.rproject.org/package=pheatmap.

Koot, E., Wu, C., Ruza, I., Hilario, E., Storey, R., Wells, R., et al. (2021). Genome-wide analysis reveals the genetic stock structure of hoki (Macruronus novaezelandiae). Evol. Appl. 14, 28482863. doi:10.1111/eva.13317.

Kraft, D. W., Conklin, E. E., Barba, E. W., Hutchinson, M., Toonen, R. J., Forsman, Z. H., et al. (2020). Genomics versus mtDNA for resolving stock structure in the silky shark (Carcharhinus falciformis). PeerJ 8. doi:10.7717/peerj.10186.

Laikre, L., Palm, S., and Ryman, N. (2005). Genetic population structure of fishes: implications for coastal zone management. AMBIO A J. Hum. Environ. 34, 111-119. doi:10.1579/0044-744734.2.111.

Lal, M. M., Southgate, P. C., Jerry, D. R., and Zenger, K. R. (2016). Fishing for divergence in a sea of connectivity: The utility of ddRADseq genotyping in a marine invertebrate, the black-lip pearl oyster Pinctada margaritifera. Mar. Genomics 25, 57-68. doi:10.1016/j.margen.2015.10.010.

Langley, A. D. (2018). Stock assessment of tarakihi off the east coast of mainland New Zealand. Wellington, New Zealand: Ministry for Primary Industries.

Li, H. (2011). A statistical framework for SNP calling, mutation discovery, association mapping and population genetical parameter estimation from sequencing data. Bioinformatics 27, 2987-2993. doi:10.1093/bioinformatics/btr509.

Li, H., and Durbin, R. (2009). Fast and accurate short read alignment with Burrows-Wheeler transform. Bioinformatics 25, 1754-1760. doi:10.1093/bioinformatics/btp324.

Li, H., Handsaker, B., Wysoker, A., Fennell, T., Ruan, J., Homer, N., et al. (2009). The Sequence Alignment/Map format and SAMtools. Bioinformatics 25, 2078-2079.

doi:10.1093/bioinformatics/btp352.

Mace, P., Ritchie, P., Wellenreuther, M., McKenzie, J., Hupman, K., Hillary, R., et al. (2020). Report of the Workshop on the Utility of Genetic Analyses for Addressing New Zealand Fisheries Questions.

McKenzie, J. R., Beentjes, M., Parker, S., Parsons, D. M., Armiger, H., Wilson, O., et al. (2017). Fishery characterisation and age composition of tarakihi in TAR 1, 2 and 3 for 2013/14 and 2014/15. Wellington, New Zealand: Ministry for Primary Industries Available at: http://www.mpi.govt.nz/news-and-resources/publications [Accessed December 1, 2017].

Mejía-Ruíz, P., Perez-Enriquez, R., Mares-Mayagoitia, J. A., and Valenzuela-Quiñonez, F. (2020). Population genomics reveals a mismatch between management and biological units in green abalone (Haliotis fulgens). PeerJ 8, e9722. doi:10.7717/peerj.9722. 
972

973

974

975

976

977

978

979

980

981

982

983

984

985

986

987

988

989

990

991

992

993

994

995

996

997

998

999

1000

1001

1002

1003

1004

1005

1006

1007

1008

1009

1010

Miller, P. A., Fitch, A. J., Gardner, M., Hutson, K. S., and Mair, G. (2011). Genetic population structure of Yellowtail Kingfish (Seriola lalandi) in temperate Australasian waters inferred from microsatellite markers and mitochondrial DNA. Aquaculture 319, 328-336.

doi:10.1016/j.aquaculture.2011.05.036.

Morrison, M. A., Jones, E. G., Parsons, D. P., and Grant, C. M. (2014). Habitats and areas of particular significance for coastal finfish fisheries management in New Zealand: A review of concepts and life history knowledge, and suggestions for future research. Wellington, New Zealand: Ministry for Primary Industries. Available at: http://www.mpi.govt.nz/newsresources/publications.aspx [Accessed December 1, 2017].

Nazareno, A. G., Bemmels, J. B., Dick, C. W., and Lohmann, L. G. (2017). Minimum sample sizes for population genomics: an empirical study from an Amazonian plant species. Mol. Ecol. Resour. 17, 1136-1147. doi:10.1111/1755-0998.12654.

Nugroho, E., Ferrell, D. J., Smith, P., and Taniguchi, N. (2001). Genetic divergence of kingfish from Japan, Australia and New Zealand inferred by microsatellite DNA and mitochondrial DNA control region markers. Fish. Sci. 67, 843-850. doi:10.1046/j.1444-2906.2001.00331.x.

Oksanen, J., Blanchet, F. G., Friendly, M., Kindt, R., Legendre, P., McGlinn, D., et al. (2020). vegan: Community Ecology Package. Available at: https://cran.r-project.org/package=vegan.

Oosting, T. (2021). Connecting the past, present and future: A population genomic study of Australasian snapper (Chrysophrys auratus) in New Zealand. [doctoral thesis]. [New Zealand]: Victoria University of Wellington. doi:10.26686/wgtn.16613959.v1

Oosting, T., Hilario, E., Wellenreuther, M., and Ritchie, P. A. (2020). DNA degradation in fish: Practical solutions and guidelines to improve DNA preservation for genomic research. Ecol. Evol. 10, 8643-8651. doi:10.1002/ece3.6558.

Orensanz, J. M., Armstrong, J., Armstrong, D., and Hilborn, R. (1998). Crustacean resources are vulnerable to serial depletion: the multifaceted decline of crab and shrimp fisheries in the Greater Gulf of Alaska. Rev. Fish Biol. Fish. 8, 117-176. doi:10.1023/A:1008891412756.

Ovenden, J. R. (2013). Crinkles in connectivity: combining genetics and other types of biological data to estimate movement and interbreeding between populations. Mar. Freshw. Res. 64, 201. doi:10.1071/mf12314.

Ovenden, J. R., Berry, O., Welch, D. J., Buckworth, R. C., and Dichmont, C. M. (2015). Ocean's eleven: a critical evaluation of the role of population, evolutionary and molecular genetics in the management of wild fisheries. Fish Fish. 16, 125-159. doi:10.1111/faf.12052.

Papa, Y., Halliwell, A. G., Morrison, M. A., Wellenreuther, M., and Ritchie, P. A. (2021a). Phylogeographic structure and historical demography of tarakihi (Nemadactylus macropterus) and king tarakihi (Nemadactylus n.sp.) in New Zealand. New Zeal. J. Mar. Freshw. Res., 1-25. doi:10.1080/00288330.2021.1912119.

Papa, Y., Oosting, T., Valenza-Troubat, N., Wellenreuther, M., and Ritchie, P. A. (2021b). Genetic stock structure of New Zealand fish and the use of genomics in fisheries management: an overview and outlook. New Zeal. J. Zool. 48, 1-31. doi:10.1080/03014223.2020.1788612. 
1011 Papa, Y., Wellenreuther, M., Morrison, M. A., and Ritchie, P. A. (2021c). Genome assembly and alternative splicing data of a highly heterozygous New Zealand fisheries species, the tarakihi (Nemadactylus macropterus). [Manuscript in prep.]

Pecoraro, C., Babbucci, M., Franch, R., Rico, C., Papetti, C., Chassot, E., et al. (2018). The population genomics of yellowfin tuna (Thunnus albacares) at global geographic scale challenges current stock delineation. Sci. Rep. 8, 1-10. doi:10.1038/s41598-018-32331-3.

Pembleton, L. W., Cogan, N. O. I., and Forster, J. W. (2013). StAMPP: an R package for calculation of genetic differentiation and structure of mixed-ploidy level populations. Mol. Ecol. Resour. 13, 946-952. doi:10.1111/1755-0998.12129.

R Core Team (2020). R: A language and environment for statistical computing. Available at: http://www.r-project.org/.

Raj, A., Stephens, M., and Pritchard, J. K. (2014). FastSTRUCTURE: Variational inference of population structure in large SNP data sets. Genetics 197, 573-589. doi:10.1534/genetics.114.164350.

Reiss, H., Hoarau, G., Dickey-Collas, M., and Wolff, W. J. (2009). Genetic population structure of marine fish: Mismatch between biological and fisheries management units. Fish Fish. 10, 361395. doi:10.1111/j.1467-2979.2008.00324.x.

Rellstab, C., Gugerli, F., Eckert, A. J., Hancock, A. M., and Holderegger, R. (2015). A practical guide to environmental association analysis in landscape genomics. Mol. Ecol. 24, 4348-4370. doi:10.1111/mec.13322.

Revelle, W. (2021). psych: Procedures for Psychological, Psychometric, and Personality Research. Available at: https://cran.r-project.org/package=psych.

Richardson, B. J. (1982). Geographical Distribution of Electrophoretically Detected Protein Variation in Australian Commercial Fishes. II.* Jackass Morwong, Cheilodactylus macropterus Bloch \& Schneider. Aust. J. Mar. Freshw. Res. 33, 927-31. Available at: http://www.publish.csiro.au/mf/pdf/MF9820927 [Accessed November 28, 2017].

Roberts, C. D., Stewart, A. L., and Struthers, C. D. (2015). The Fishes of New Zealand. eds. C. D. Roberts, A. L. Stewart, and C. D. Struthers. Wellington, New Zealand: Te Papa Press.

Roberts, C. D., Stewart, A. L., Struthers, C. D., Barker, J. J., and Kortet, S. (2020). Checklist of the Fishes of New Zealand. Online version 1.2. Museum New Zeal. Te Papa Tongarewa, Wellingt., 241. Available at: https://collections.tepapa.govt.nz/document/10564 [Accessed September 15, 2020].

RStudio Team (2020). RStudio: Integrated development environment for R. Available at: http://www.rstudio.com/.

Sandoval-Castillo, J., Robinson, N. A., Hart, A. M., Strain, L. W. S., and Beheregaray, L. B. (2018). Seascape genomics reveals adaptive divergence in a connected and commercially important mollusc, the greenlip abalone (Haliotis laevigata), along a longitudinal environmental gradient. Mol. Ecol. 27, 1603-1620. doi:10.1111/mec.14526. 
1049

1050

1051

1052

1053

1054

1055

1056

1057

1058

1059

1060

1061

1062

1063

1064

1065

1066

1067

1068

1069

1070

1071

1072

1073

1074

1075

1076

1077

1078

1079

1080

1081

1082

1083

1084

1085

Sbrocco, E. J., and Barber, P. H. (2013). MARSPEC: ocean climate layers for marine spatial ecology. Ecology 94, 979-979. doi:10.1890/12-1358.1.

Smith, P. J., Roberts, C. D., McVeagh, S. M., and Benson, P. G. (1996). Genetic evidence for two species of tarakihi (Teleostei: Cheilodactylidae: Nemadactylus) in New Zealand waters. New Zeal. J. Mar. Freshw. Res. 30, 209-220. doi:10.1080/00288330.1996.9516709.

Smith, P. J., Steinke, D., Smith, P. J., Steinke, D., Mcmillan, P. J., Mcveagh, S. M., et al. (2008). DNA database for commercial marine fish. Wellington, New Zealand: National Institute of Water and Atmospheric Research.

Thresher, R. E., Proctor, C. H., and Gunn, J. S. (1994). An evaluation of electron-probe microanalysis of otoliths for stock delineation and identification of nursery areas in a southern temperate groundfish, Nemadactylus macropterus (Cheilodactylidae). Fish. Bull. 92, 817-840. Available at: https://spo.nmfs.noaa.gov/sites/default/files/pdf-content/1994/924/thresher.pdf [Accessed November 21, 2017].

Tong, L. J., and Vooren, C. M. (1972). The biology of the New Zealand tarakihi, Cheilodactylus macropterus (Bloch and Schneider). Wellington, New Zealand: New Zealand Ministry of Agriculture and Fisheries.

Tyberghein, L., Verbruggen, H., Pauly, K., Troupin, C., Mineur, F., and De Clerck, O. (2012). BioORACLE: a global environmental dataset for marine species distribution modelling. Glob. Ecol. Biogeogr. 21, 272-281. doi:10.1111/j.1466-8238.2011.00656.x.

van Etten, J. (2017). R package gdistance: Distances and routes on geographical grids. J. Stat. Softw. 76, 1-21. doi:10.18637/jss.v076.i13.

Vaux, F., Bohn, S., Hyde, J. R., and O’Malley, K. G. (2021). Adaptive markers distinguish North and South Pacific Albacore amid low population differentiation. Evol. Appl., 1-22. doi:10.1111/eva.13202.

Vooren, C. M. (1972). Postlarvae and juveniles of the tarakihi (teleostei: Cheilodactylidae) in New Zealand. New Zeal. J. Mar. Freshw. Res. 6, 602-618. doi:10.1080/00288330.1972.9515448.

Waples, R. S., and Gaggiotti, O. (2006). What is a population? An empirical evaluation of some genetic methods for identifying the number of gene pools and their degree of connectivity. Mol. Ecol. 15, 1419-1439. doi:10.1111/j.1365-294X.2006.02890.x.

Waples, R. S., Punt, A. E., and Cope, J. M. (2008). Integrating genetic data into management of marine resources: How can we do it better? Fish Fish. 9, 423-449. doi:10.1111/j.14672979.2008.00303.x.

Weir, B. S., and Cockerham, C. C. (1984). Estimating F-statistics for the analysis of population structure. Evolution 38, 1358-1370.

Whitlock, M. C., and Lotterhos, K. E. (2015). Reliable detection of loci responsible for local adaptation: inference of a null model through trimming the distribution of $\mathrm{F}_{\text {ST. }}$ Am. Nat. 186, S24-S36. doi:10.1086/682949. 
1086 Wickham, H. (2009). ggplot2: elegant graphics for data analysis. 1st ed. New York, NY: Springer doi:10.1007/978-0-387-98141-3.

1088 Willing, E., Dreyer, C., and van Oosterhout, C. (2012). Estimates of genetic differentiation measured by $F_{\mathrm{ST}}$ do not necessarily require large sample sizes when using many SNP markers. PLoS One 7, e42649. doi:10.1371/journal.pone.0042649.

Ying, Y., Chen, Y., Lin, L., and Gao, T. (2011). Risks of ignoring fish population spatial structure in fisheries management. Can. J. Fish. Aquat. Sci. 68, 2101-2120. doi:10.1139/f2011-116.

1093 Zhou, S., Kolding, J., Garcia, S. M., Plank, M. J., Bundy, A., Charles, A., et al. (2019). Balanced harvest: concept, policies, evidence, and management implications. Rev. Fish Biol. Fish. 29, 711-733. doi:10.1007/s11160-019-09568-w.

\section{Data Availability Statement}

1097 The datasets generated for this study can be found in the Genomics Aotearoa repository

1098 [https://data.agdr.org.nz]. All bash and R scripts used for this study are available on GitHub on the

1099 following repository: https://github.com/yvanpapa/tarakihi_population_genomics. 


\section{Figures}
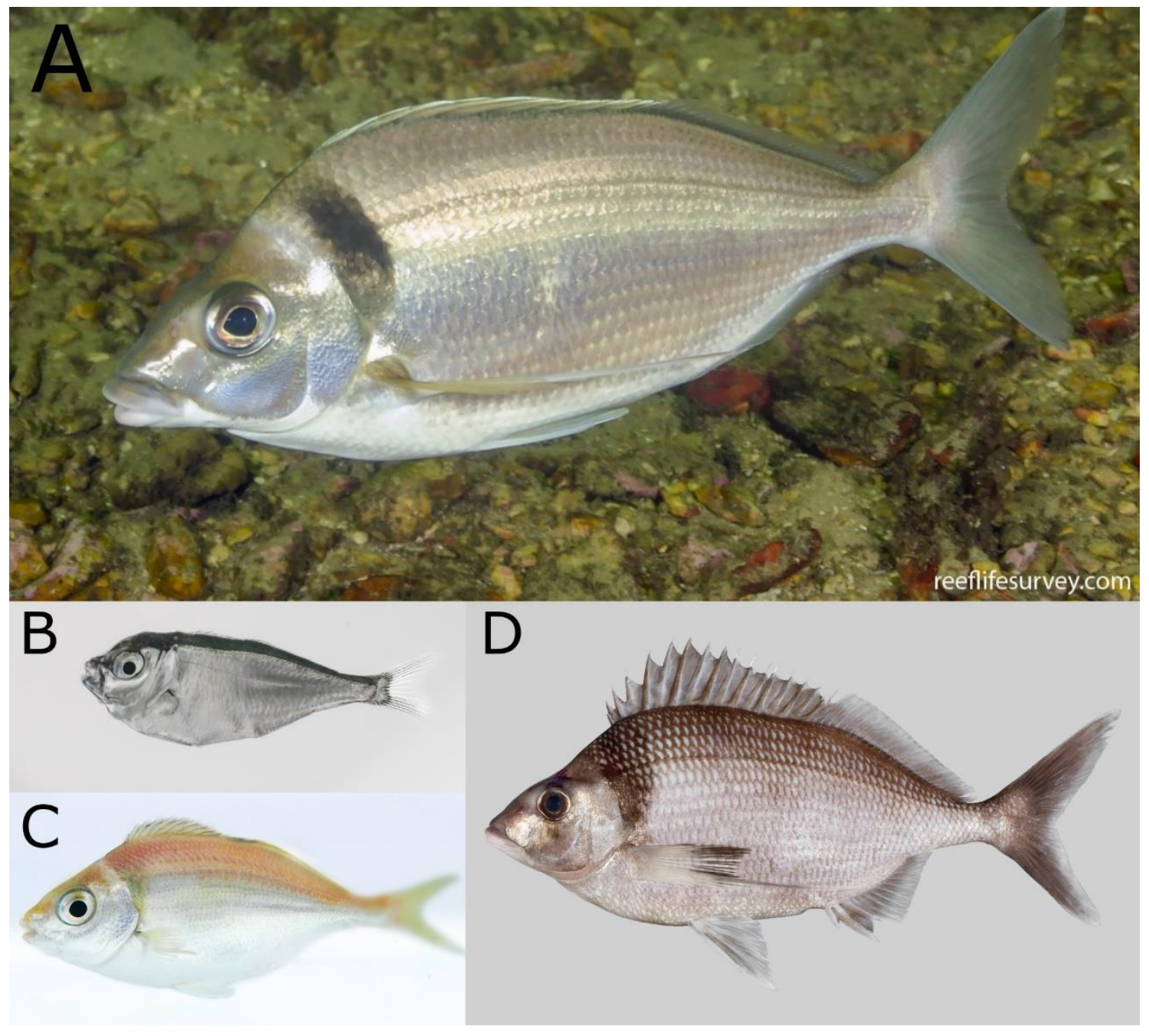

1102 Figure 1. (A) An adult tarakihi (Nemadactylus macropterus) in Port Davey, Tasmania. In the late1103 larval stage (B), the individuals display a deep body with a strong ventral keel particularly adapted to 1104 pelagic life. This "paperfish" stage is thought to be an important stage for dispersal of tarakihi due to 1105 its duration (c. 10 months) and the strong influence of oceanic currents on its spatial distribution. 1106 Metamorphosis into the juvenile stage (C) occurs when the fish are 7-12 months old and 7-9 cm 1107 long. At this stage, the individuals settle in "nurseries" and become more sedentary. (D) King tarakihi 1108 (Nemadactylus n.sp); the main visually recognizable difference to tarakihi is the presence of a black 1109 band on the pectoral fin. Pictures by courtesy of (A) Ian Shaw, Reef Life Survey, (B-C) Robert 1110 Lamberts, the New Zealand Institute for Plant and Food Research Limited, and (D) the Museum of 1111 New Zealand Te Papa Tongarewa. 


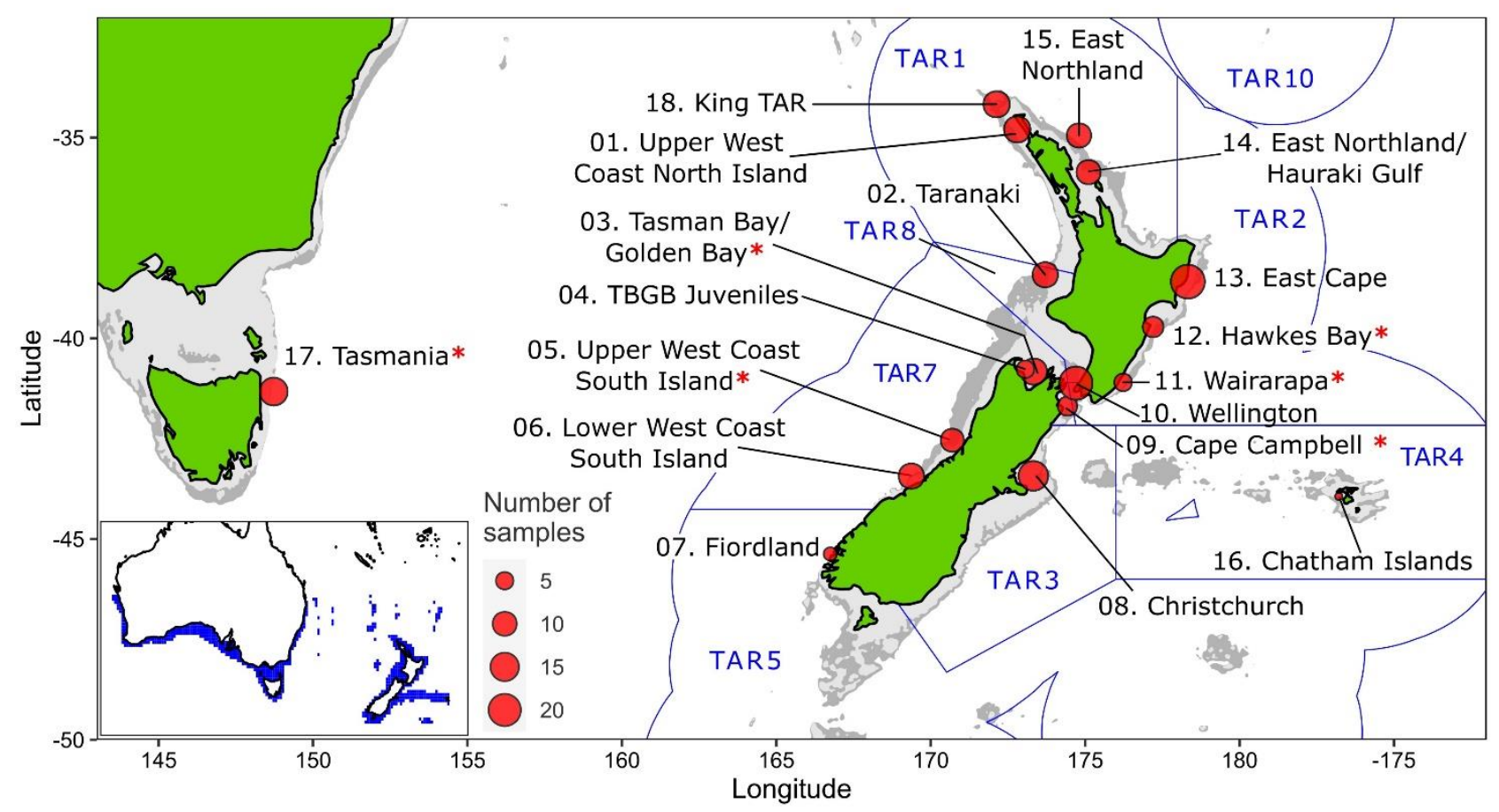

1113 Figure 2. Sampling sites of tarakihi (sites 1-17) and king tarakihi (site 18) used in this study. King 1114 TAR: king tarakihi from Three Kings Islands. Red asterisks (*) indicate populations that are 1115 adaptively divergent based on outlier analysis. Blue lines and labels correspond to the New Zealand 1116 Exclusive Economic Zone and the quota management areas for tarakihi (TAR 1-5, 7-8, 10). The 1117 bathymetric contour is shown in light grey $(125 \mathrm{~m})$ and dark grey $(1000 \mathrm{~m})$. Bottom left: range of 1118 tarakihi in blue area (Kaschner et al., 2019). 
bioRxiv preprint doi: https://doi.org/10.1101/2022.02.10.479861; this version posted February 10, 2022. The copyright holder for this preprint (which was not certified by peer review) is the author/funder, who has granted bioRxiv a license to display the preprint in perpetuity. It is made available under aCC-BY 4.0 International license.

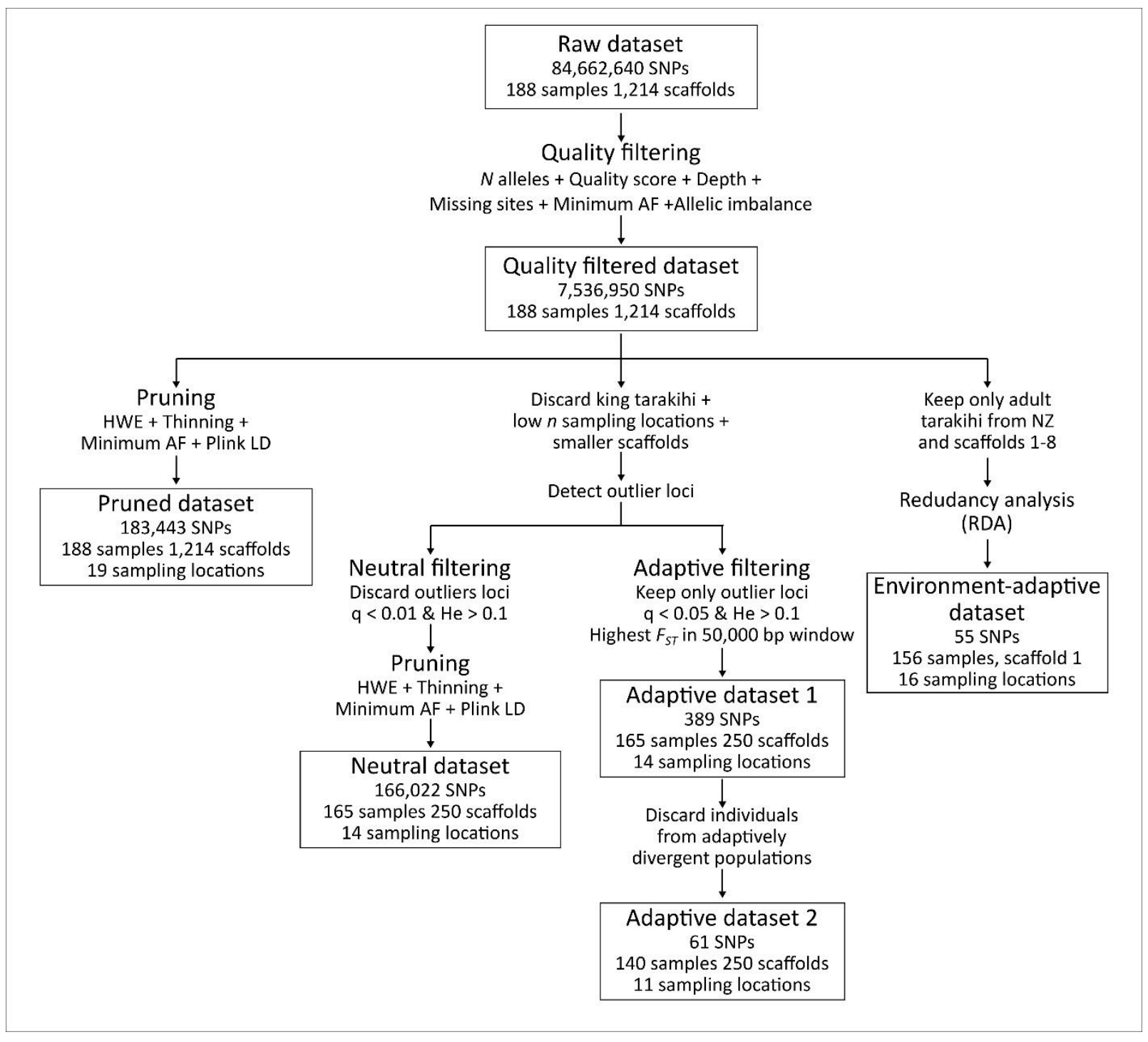

1120 Figure 3. Variant filtering pipeline applied on the raw SNP dataset, resulting in one intermediary 1121 dataset (quality-filtered) and five final datasets (pruned, neutral, adaptive 1, adaptive 2, and 1122 environment-adaptive). 

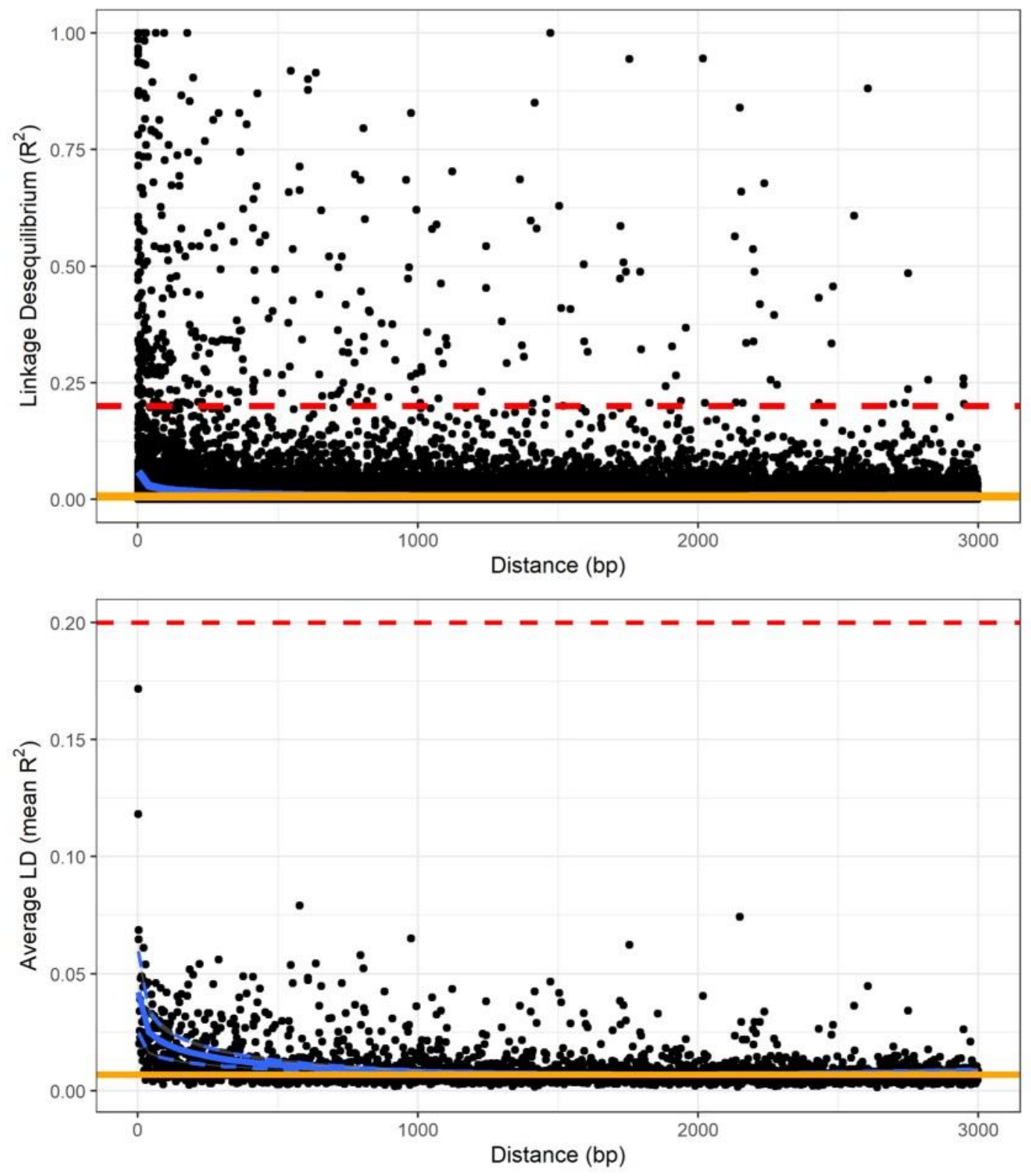

1124 Figure 4. Linkage disequilibrium decay over genetic distance on scaffold 1, calculated on the quality-filtered SNP dataset, minus king tarakihi specimens. The horizontal red dashed line shows the threshold of 0.2 that is commonly applied to identify independent degradation of nucleotide sites. The orange line is the background level of linkage disequilibrium (intercept). The blue line is the trend of linkage disequilibrium decay fitted to the plot (minimum and maximum variance in dashed lines for the mean). 


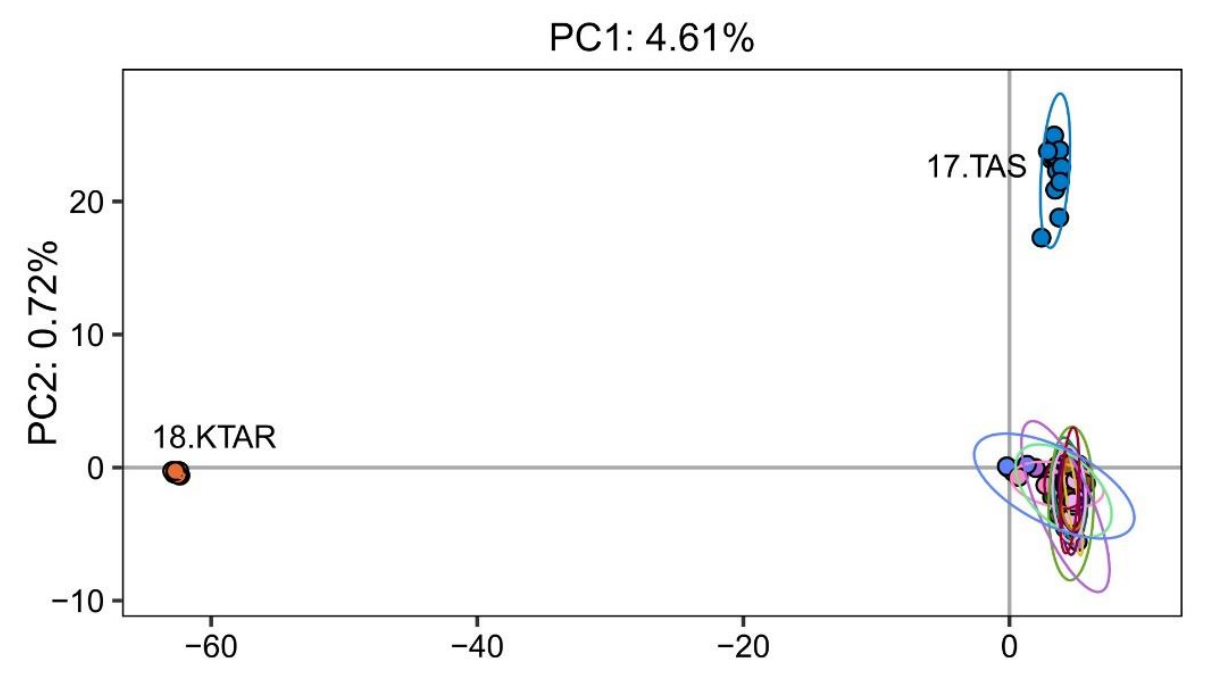

locations

O 01.UWCNI

O 02.TARA

O 03. TBGB

○ 04.TBGBJ

O 05.UWCSI

0 06.LWCSI

○ 07.FRDL

- $08 . \mathrm{CHCH}$

O 09.CC

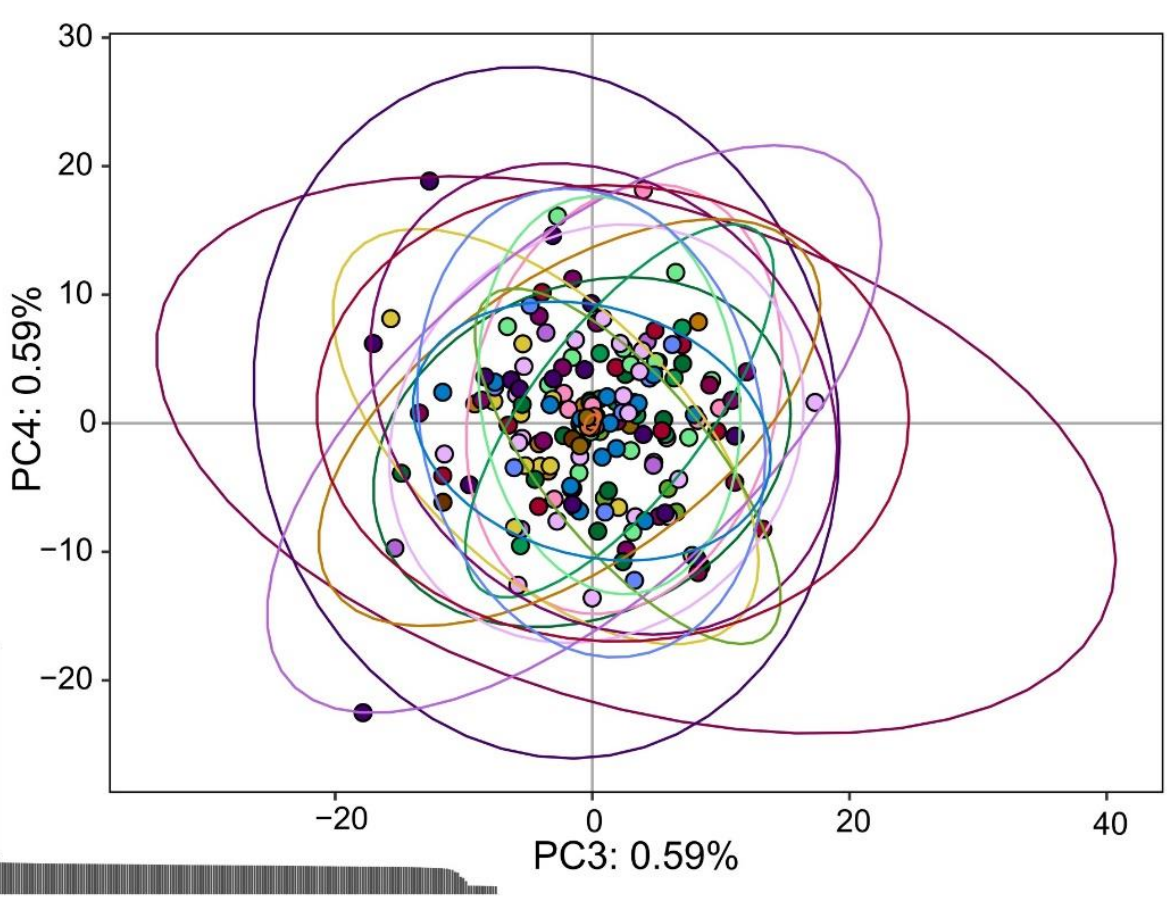

O 10.WGTN

O 11.WAI

O 12.HB

O 13.EC

- 14.ENHG

O 15.ENLD

- 16.CHAT

○ 17.TAS

18.KTAR

- GBK ㄷ.

1131 Figure 5. Principal component analysis of the pruned SNP dataset that includes 183,443 loci from 188 tarakihi and king tarakihi. Ellipses represent the 95\% confidence intervals. Top: Axes 1 and 2. Bottom: Axes 3 and 4. Bottom left: Eigenvalues. Sampling location codes as referred to in Table 1. 

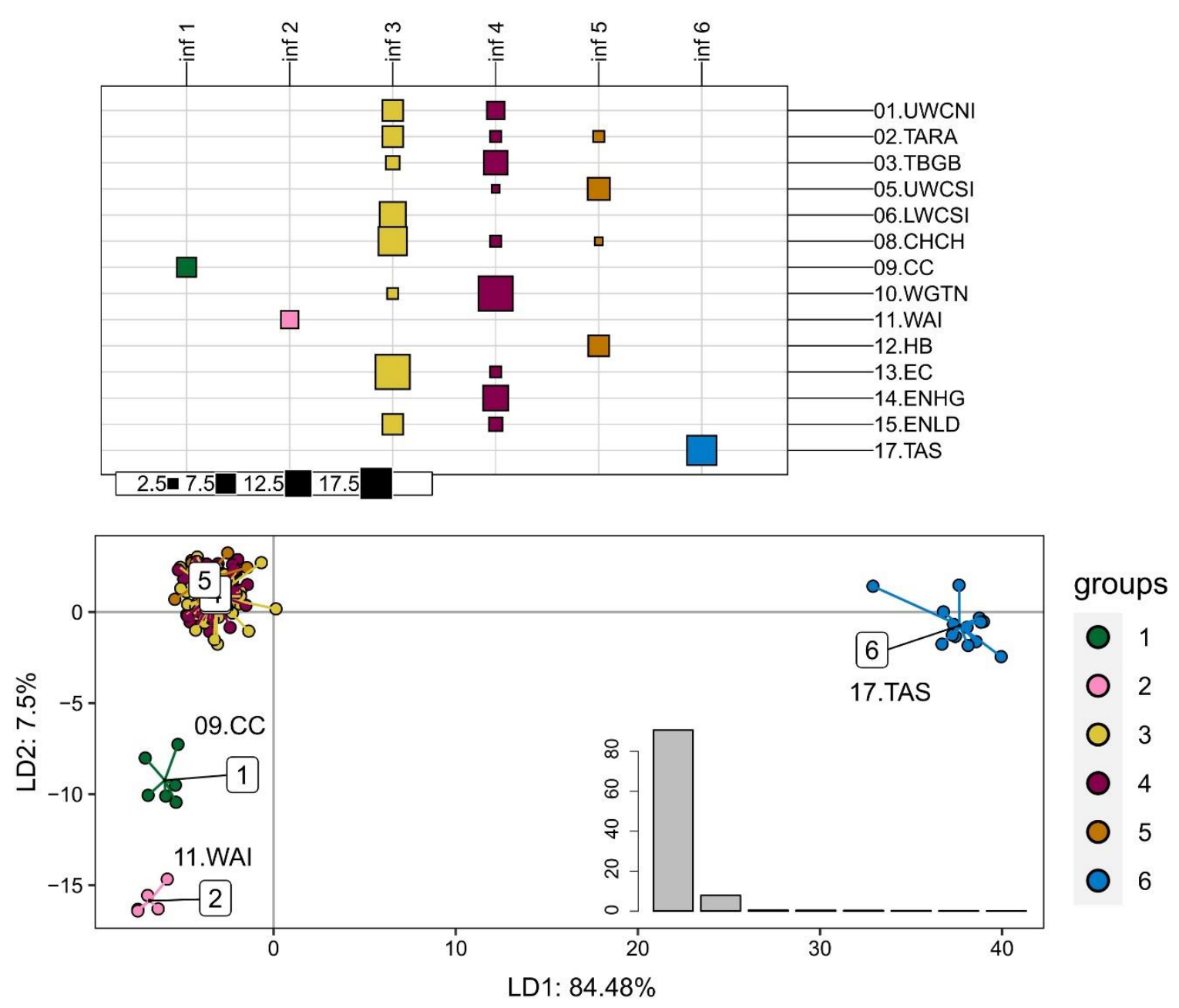

1134

1135 Figure 6. Discriminant analysis of principal components of the first adaptive SNP datasets that 1136 include 389 loci from 165 tarakihi. Top: results of the $K$-means clustering analysis, with colours 1137 corresponding to inferred groups (inf). Bottom: Projection of the DAPC based on inferred groups. 1138 Bottom right: Discriminant analysis eigenvalues. Sampling location codes as referred to in Table 1. 


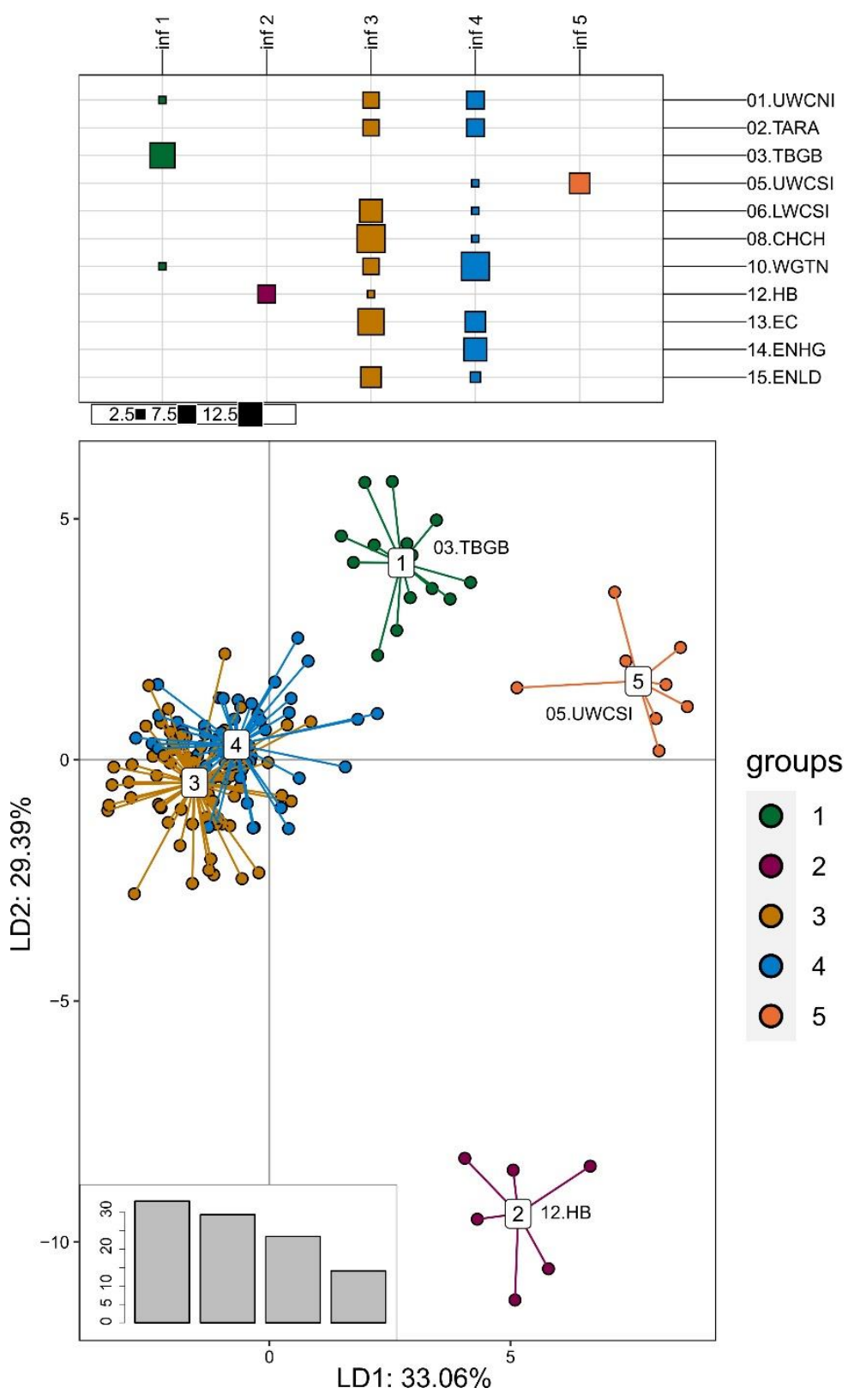

1140 Figure 7. Discriminant analysis of principal components of the second adaptive SNP dataset that 1141 include 61 loci from 140 tarakihi. Top: results of the $K$-means clustering analysis, with colours 1142 corresponding to inferred groups (inf). Bottom: Projection of the DAPC based on inferred groups. 1143 Bottom left: Discriminant analysis eigenvalues. Sampling location codes as referred to in Table 1. 
bioRxiv preprint doi: https://doi.org/10.1101/2022.02.10.479861; this version posted February 10,2022 . The copyright holder for this preprint (which was not certified by peer review) is the author/funder, who has granted bioRxiv a license to display the preprint in perpetuity. It is made available under aCC-BY 4.0 International license.

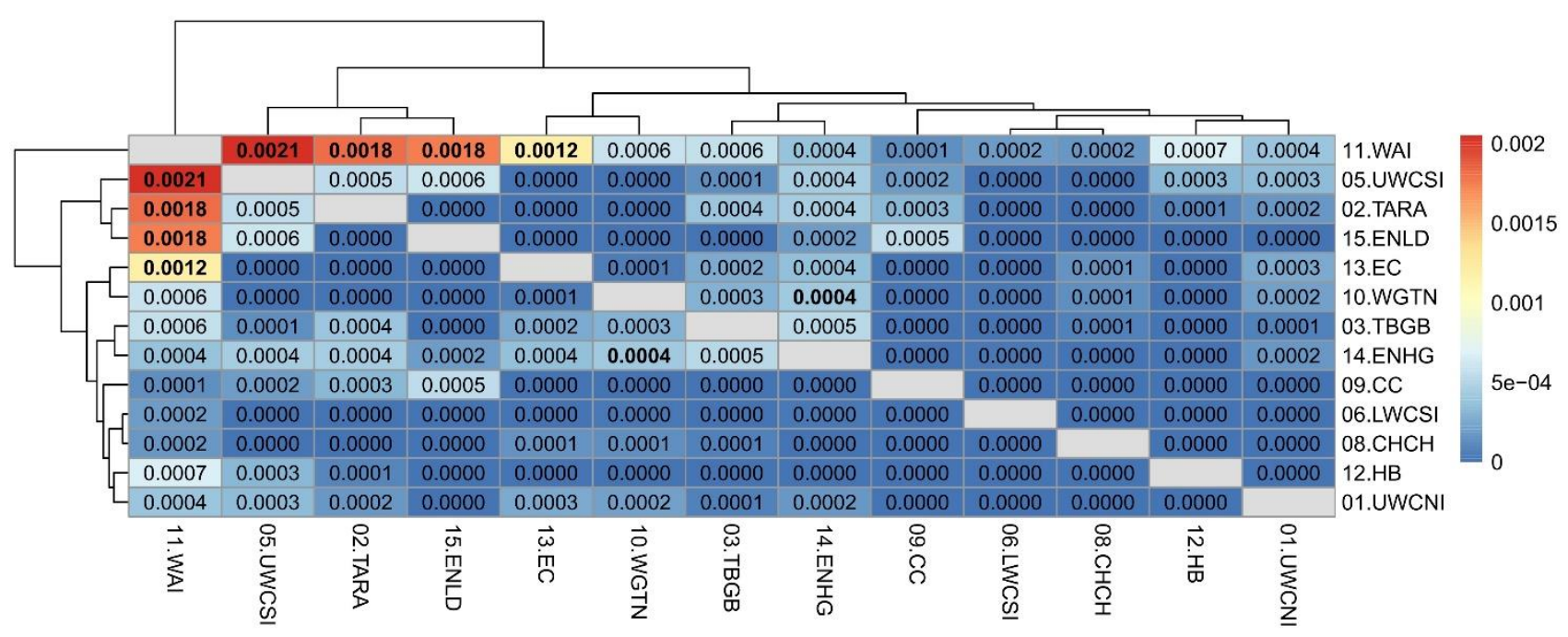

1145 Figure 8. Heatmap of pairwise weighted $F_{\mathrm{ST}}$ estimates (corresponding to the values above and below 1146 the diagonal) among sample locations of the neutral SNP dataset, minus Tasmania. The dendrogram 1147 shows the inferred relationship between sample locations. Significant $p$-values $(\leq 0.05$ after false 1148 discovery rate correction) are in bold.

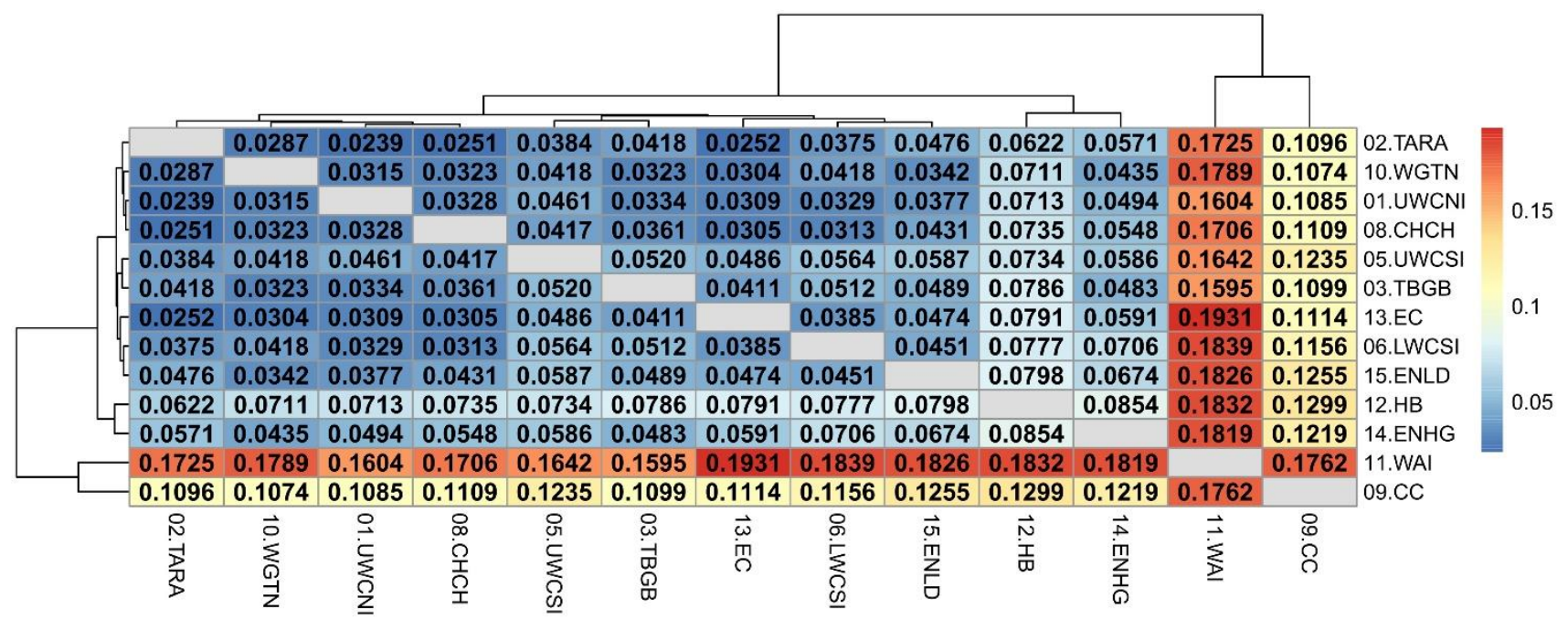

1150 Figure 9. Heatmap of pairwise weighted $F_{\text {ST }}$ estimates (corresponding to the values above and below 1151 the diagonal) among sample locations of the adaptive SNP dataset, minus Tasmania. The dendrogram 1152 shows the inferred relationship between sample locations. Significant $p$-values $(<0.01$ after false 1153 discovery rate correction) are in bold. 


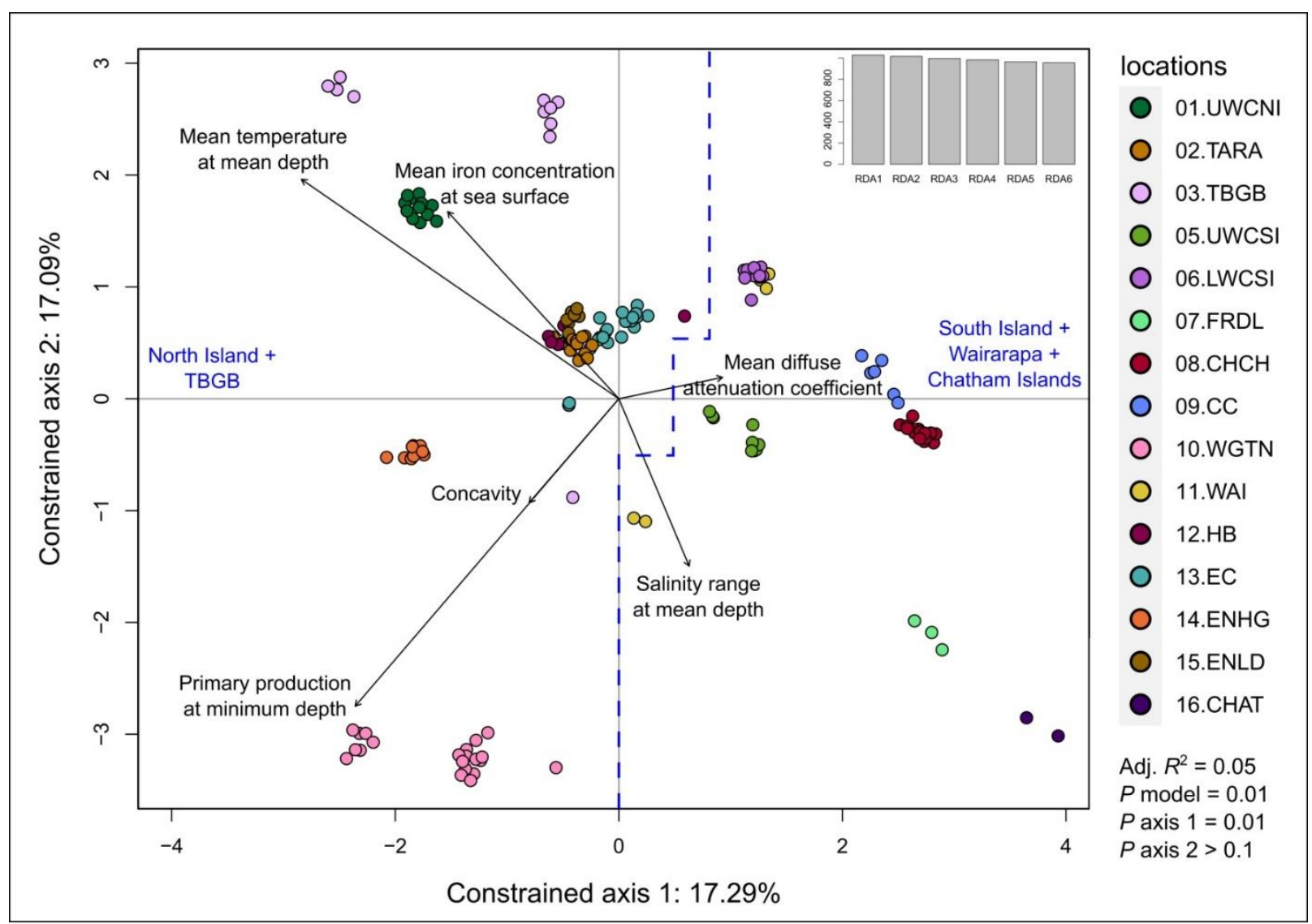

1155 Figure 10. Redundancy analysis (RDA) performed on the quality-filtered SNP dataset from scaffold 1156 1, restricted to adult tarakihi from New Zealand. This included 108,903 loci from 156 tarakihi. The 1157 two constrained axes show samples from 16 localities in relation to six lowly correlated 1158 environmental variables (black arrows). All samples on the left of the blue dashed line are from 1159 North Island and Tasman Bay/Golden Bay, while all samples on the right are from South Island, 1160 Wairarapa and Chatham Islands. Top right: Eigenvalues. Sampling location codes as referred to in 1161 Table 5.1. 


\section{Tables}

1163 Table 1. Sampling sites and sample information.

\begin{tabular}{|c|c|c|c|c|c|c|}
\hline $\begin{array}{l}\text { Management } \\
\text { area }\end{array}$ & $N$ & Sampling location & $N$ & Code & Source of sample & $\begin{array}{l}\text { Sampling phase ( } n \\
\text { samples) }\end{array}$ \\
\hline \multicolumn{7}{|l|}{ Tarakihi } \\
\hline \multirow[t]{3}{*}{ TAR1 } & 32 & $\begin{array}{l}\text { Upper West Coast } \\
\text { North Island }\end{array}$ & 12 & 01.UWCNI & NIWA 2019 survey & $2(12)$ \\
\hline & & $\begin{array}{l}\text { East Northland / } \\
\text { Hauraki Gulf }\end{array}$ & 10 & 14.ENHG & NIWA 2019 survey & $2(10)$ \\
\hline & & East Northland & 10 & 15.ENLD & $\begin{array}{l}\text { Commercial fishing / } \\
\text { NIWA } 2019 \text { survey }\end{array}$ & $1(1) / 2(9)$ \\
\hline \multirow[t]{4}{*}{ TAR2 } & 33 & Wellington & 21 & 10.WGTN & $\begin{array}{l}\text { Commercial fishing / } \\
\text { Fishing competition }\end{array}$ & $1(1) / 2(20)$ \\
\hline & & Wairarapa & 5 & 11.WAI & Commercial fishing & $1(5)$ \\
\hline & & Hawke's Bay & 7 & 12.HB & $\begin{array}{l}\text { Commercial fishing / } \\
\text { Fishing competition }\end{array}$ & $1(1) / 2(6)$ \\
\hline & & East Cape & 21 & 13.EC & $\begin{array}{l}\text { Commercial fishing / } \\
\text { Fishing competition }\end{array}$ & $1(4) / 2(17)$ \\
\hline TAR3 & 16 & Christchurch & 16 & 08. $\mathrm{CHCH}$ & NIWA 2020 survey & $2(16)$ \\
\hline TAR4 & 2 & Chatham Islands* & 2 & 16.CHAT & Commercial fishing & $1(2)$ \\
\hline TAR5 & 3 & Fiordland* & 3 & 07.FRDL & Recreational fishers & $1(3)$ \\
\hline \multirow[t]{5}{*}{ TAR7 } & 43 & $\begin{array}{l}\text { Tasman Bay / } \\
\text { Golden Bay }\end{array}$ & 12 & 03.TBGB & NIWA 2019 survey & $2(12)$ \\
\hline & & TBGB juveniles* & 5 & 04.TBGBJ & NIWA 2019 survey & $2(5)$ \\
\hline & & $\begin{array}{l}\text { Upper West Coast } \\
\text { South Island }\end{array}$ & 9 & 05.UWCSI & Commercial fishing & $1(9)$ \\
\hline & & $\begin{array}{l}\text { Lower West Coast } \\
\text { South Island }\end{array}$ & 11 & 06.LWCSI & NIWA 2019 survey & $2(11)$ \\
\hline & & Cape Campbell & 6 & 09.CC & Commercial fishing & $1(6)$ \\
\hline TAR8 & 32 & Taranaki & 11 & 02.TARA & $\begin{array}{l}\text { Commercial fishing / } \\
\text { NIWA } 2019 \text { survey }\end{array}$ & $1(3) / 2(8)$ \\
\hline Australia & 14 & Tasmania & 14 & 17.TAS & NSW DPI 2019 survey & $2(14)$ \\
\hline \multicolumn{7}{|l|}{ King Tarakihi } \\
\hline TAR1 & 12 & $\begin{array}{l}\text { Three Kings } \\
\text { Islands* }\end{array}$ & 12 & 18.KTAR & Commercial fishing & $1(12)$ \\
\hline TAR2 & 1 & East Cape* & 1 & GBK & Fishing competition & $2(1)$ \\
\hline
\end{tabular}

1164 Note: $\left({ }^{*}\right)$ Samples that were not included in the final neutral and adaptive datasets. NIWA: National 1165 Institute of Water and Atmospheric Research. Sampling locations and corresponding codes are 1166 plotted on the map in Figure 2. 
Population genomics of tarakihi

Table 2. Results from analysis of molecular variance performed on the neutral and adaptive SNP datasets, with seven a priori groupings.

\begin{tabular}{|c|c|c|c|c|c|c|c|c|c|c|c|c|c|c|c|}
\hline \multirow[b]{2}{*}{ A priori grouping } & \multirow[b]{2}{*}{$N$ ind. } & \multirow[b]{2}{*}{$N$ locs } & \multirow[b]{2}{*}{$N$ groups } & \multicolumn{3}{|c|}{ Among groups } & \multicolumn{3}{|c|}{$\begin{array}{c}\text { Between locs within } \\
\text { groups }\end{array}$} & \multicolumn{3}{|c|}{ Between ind. within locs } & \multicolumn{3}{|c|}{ Within individuals } \\
\hline & & & & $\% \operatorname{Var}$ & $\Phi$ & $P$ & $\% \operatorname{Var}$ & $\Phi$ & $P$ & $\% \operatorname{Var}$ & $\Phi$ & $P$ & $\% \operatorname{Var}$ & $\Phi$ & $P$ \\
\hline \multicolumn{16}{|l|}{ Neutral } \\
\hline no grouping & 165 & 14 & & & & & 0.084 & 0.001 & 0.001 & -0.260 & -0.003 & 0.565 & 100.176 & -0.002 & 0.593 \\
\hline $\begin{array}{l}\text { no grouping, NZ } \\
\text { only }\end{array}$ & 151 & 13 & & & & & -0.011 & 0.000 & 0.769 & -0.314 & -0.003 & 0.625 & 100.324 & -0.003 & 0.640 \\
\hline NZ TAR areas + AU & 165 & 14 & 6 & 0.104 & 0.001 & 0.123 & -0.005 & 0.000 & 0.725 & -0.260 & -0.003 & 0.609 & 100.161 & -0.002 & 0.586 \\
\hline NZ TAR areas only & 151 & 13 & 5 & 0.002 & 0.000 & 0.501 & -0.012 & 0.000 & 0.731 & -0.314 & -0.003 & 0.611 & 100.324 & -0.003 & 0.620 \\
\hline NZ West vs. East & 130 & 12 & 2 & 0.002 & 0.000 & 0.261 & -0.009 & 0.000 & 0.671 & -0.322 & -0.003 & 0.592 & 100.329 & -0.003 & 0.642 \\
\hline $\begin{array}{l}\text { NZ North Island: } \\
\text { West vs. East }\end{array}$ & 76 & 7 & 2 & -0.001 & 0.000 & 0.497 & 0.010 & 0.000 & 0.462 & 0.061 & 0.001 & 0.417 & 99.930 & 0.001 & 0.449 \\
\hline $\begin{array}{l}\text { NZ South Island: } \\
\text { West vs. East }\end{array}$ & 54 & 5 & 2 & 0.018 & 0.000 & 0.109 & -0.033 & 0.000 & 0.967 & -0.861 & -0.009 & 0.654 & 100.876 & -0.009 & 0.678 \\
\hline \multicolumn{16}{|l|}{ Adaptive } \\
\hline no grouping & 165 & 14 & & & & & 20.459 & 0.205 & 0.001 & 1.176 & 0.015 & 0.10 & 78.365 & 0.216 & 0.001 \\
\hline $\begin{array}{l}\text { no grouping, NZ } \\
\text { only }\end{array}$ & 151 & 13 & & & & & 6.060 & 0.061 & 0.001 & 1.632 & 0.017 & 0.07 & 92.308 & 0.077 & 0.001 \\
\hline NZ TAR areas + AU & 165 & 14 & 6 & 16.006 & 0.160 & 0.202 & 6.341 & 0.075 & 0.001 & 1.148 & 0.015 & 0.10 & 76.505 & 0.235 & 0.001 \\
\hline NZ TAR areas only & 151 & 13 & 5 & -2.073 & -0.021 & 0.969 & 7.786 & 0.076 & 0.001 & 1.638 & 0.017 & 0.08 & 92.649 & 0.074 & 0.001 \\
\hline NZ West vs. East & 130 & 12 & 2 & -0.634 & -0.006 & 0.970 & 6.923 & 0.069 & 0.001 & 1.609 & 0.017 & 0.08 & 92.102 & 0.079 & 0.001 \\
\hline $\begin{array}{l}\text { NZ North Island: } \\
\text { West vs. East }\end{array}$ & 76 & 7 & 2 & -1.816 & -0.018 & 0.960 & 7.140 & 0.070 & 0.001 & 3.074 & 0.032 & 0.06 & 91.601 & 0.084 & 0.001 \\
\hline $\begin{array}{l}\text { NZ South Island: } \\
\text { West vs. East }\end{array}$ & 54 & 5 & 2 & -1.436 & -0.014 & 0.909 & 7.181 & 0.071 & 0.001 & 0.931 & 0.010 & 0.32 & 93.323 & 0.067 & 0.001 \\
\hline
\end{tabular}

Note: $\%$ Var = variance component in percentage of the total variation. The three 'West vs. East' groupings did not include the Wellington location. Significant $p$-values $(\leq 0.05)$ are in bold. 
bioRxiv preprint doi: https://doi.org/10.1101/2022.02.10.479861; this version posted February 10, 2022. The copyright holder for this preprint (which was not certified by peer review) is the author/funder, who has granted bioRxiv a license to display the preprint in perpetuity. It is made available under aCC-BY 4.0 International license. 